\title{
Betulinic Acid Decorated with Polar Groups and Blue Emitting BODIPY Dye: Synthesis, Cytotoxicity, Cell-Cycle Analysis and Anti-HIV Profiling
}

\author{
David Kodr ${ }^{1,+} \mathbb{D}^{\circ}$, Jarmila Stanková ${ }^{2,+}$, Michaela Rumlová $^{3}{ }^{\mathbb{D}}$, Petr Džubák ${ }^{2}{ }^{2}$, Jiří Řehulka ${ }^{2}$, \\ Tomáš Zimmermann ${ }^{1}{ }^{1}$, Ivana Kř́žžová ${ }^{3}{ }^{\circledR}$, Soňa Gurská ${ }^{2}$, Marián Hajdúch ${ }^{2}$, Pavel B. Drašar ${ }^{1}(\mathbb{D}$ \\ and Michal Jurášek $1, * \mathbb{D}$ \\ 1 Department of Chemistry of Natural Compounds, University of Chemistry and Technology Prague, \\ 16628 Prague, Czech Republic; david.kodr@vscht.cz (D.K.); tomas.zimmermann@vscht.cz (T.Z.); \\ pavel.drasar@vscht.cz (P.B.D.) \\ 2 Institute of Molecular and Translational Medicine, Faculty of Medicine and Dentistry, \\ Palacký University and University Hospital in Olomouc, 77900 Olomouc, Czech Republic; \\ jarmila.stankova@upol.cz (J.S.); petr.dzubak@upol.cz (P.D.); jiri.rehulka@upol.cz (J.̌̌.); \\ sona.gurska@upol.cz (S.G.); marian.hajduch@upol.cz (M.H.) \\ 3 Department of Biotechnology, University of Chemistry and Technology Prague, \\ 16628 Prague, Czech Republic; michaela.rumlova@vscht.cz (M.R.); ivana.krizova@vscht.cz (I.K.) \\ * Correspondence: michal.jurasek@vscht.cz \\ + These authors have contributed equally to this work.
}

Citation: Kodr, D.; Stanková, J.; Rumlová, M.; Džubák, P.; Řehulka, J.; Zimmermann, T.; Kř́ižová, I.; Gurská,

S.; Hajdúch, M.; Drašar, P.B.; et al. Betulinic Acid Decorated with Polar Groups and Blue Emitting BODIPY Dye: Synthesis, Cytotoxicity, Cell-Cycle Analysis and Anti-HIV Profiling. Biomedicines 2021, 9, 1104 https://doi.org/10.3390/

biomedicines 9091104

Academic Editor: Jun Lu

Received: 3 August 2021

Accepted: 21 August 2021

Published: 28 August 2021

Publisher's Note: MDPI stays neutral with regard to jurisdictional claims in published maps and institutional affiliations.

Copyright: (c) 2021 by the authors. Licensee MDPI, Basel, Switzerland. This article is an open access article distributed under the terms and conditions of the Creative Commons Attribution (CC BY) license (https:// creativecommons.org/licenses/by/ $4.0 /$ )

\begin{abstract}
Betulinic acid (BA) is a potent triterpene, which has shown promising potential in cancer and HIV-1 treatment. Here, we report a synthesis and biological evaluation of 17 new compounds, including BODIPY labelled analogues derived from BA. The analogues terminated by amino moiety showed increased cytotoxicity (e.g., BA had on CCRF-CEM IC $50>50 \mu \mathrm{M}$, amine $3 \mathrm{IC}_{50} 0.21$ and amine $14 \mathrm{IC}_{50}$ 0.29). The cell-cycle arrest was evaluated and did not show general features for all the tested compounds. A fluorescence microscopy study of six derivatives revealed that only 4 and 6 were detected in living cells. These compounds were colocalized with the endoplasmic reticulum and mitochondria, indicating possible targets in these organelles. The study of anti-HIV-1 activity showed that $8, \mathbf{1 0}, \mathbf{1 6}, 17$ and 18 have had $\mathrm{IC}_{50 \mathrm{i}}>10 \mu \mathrm{M}$. Only completely processed p24 CA was identified in the viruses formed in the presence of compounds 4 and $\mathbf{1 2}$. In the cases of 2, 8, 9, 10, 16, 17 and 18, we identified not fully processed p24 CA and p25 CA-SP1 protein. This observation suggests a similar mechanism of inhibition as described for bevirimat.
\end{abstract}

Keywords: betulinic acid; BODIPY; bevirimat; cytotoxicity; cancer; cell-cycle; fluorescent microscopy; maturation inhibitor

\section{Introduction}

Betulinic acid (BA) is a natural pentacyclic triterpene of the lupane type (Figure 1). Despite its low solubility in aqueous solutions, this substance is gaining attention with its wide range of interesting biological activity. BA is often derivatized to increase solubility, enhance the therapeutic effect, and target the drug to the specific site of action [1]. BA shows a significant degree of selectivity for cytotoxicity against a variety of tumour cells mboxciteB2-biomedicines-1332342,B3-biomedicines-1332342,B4-biomedicines-1332342 and activity against HIV-1 [5]. There are several possible mechanisms of action of BA (reviewed in [6]), which provide an advantage in the development of resistance to one of the mechanisms and may thus find application in the treatment of tumours resistant to current chemotherapeutics [6]. One is the direct action of BA on the mitochondrial membrane, leading to an increase of outer membrane permeability, its depolarization and release of cytochrome $c$ into the cytosol. It is then responsible for triggering apoptosis [7]. Among 
other effects of BA, reactive oxygen species can be formed causing non-specific damage to mitochondria [8,9], followed by the induction of caspase activity [10]. BA exhibits topoisomerase I28 inhibitory activity, and through the proteasome-dependent independent regulatory pathway, is responsible for the function of the transcription factors Sp1, Sp3 and Sp4 inhibition [11]. It is also able to inhibit the activation of the stress transcription factor NF- $к B$ [12]. A slightly different way in which tumour growth is inhibited is a complete or partial slowing of angiogenesis [13]. Later studies have shown that the antiangiogenic effect is achieved via modulation of mitochondria [14].

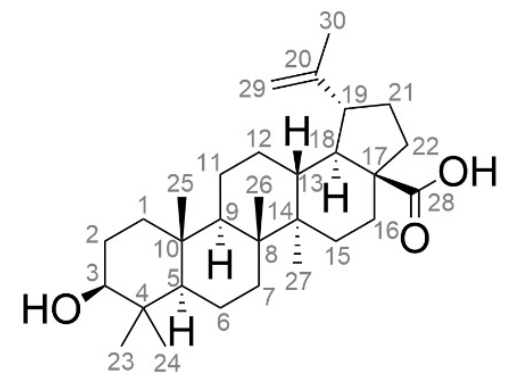

Betulinic acid

(BA)<smiles>C=C(C)[C@@H]1CCC2(C(=O)O)CC[C@H]3[C@H]4CC[C@H]5C(C)(C)[C@@H](OC(=O)CC(C)(C)C(=O)O)CC[C@]5(C)[C@H]4CC[C@H]3[C@H]12</smiles>

Bevirimat

(BT)

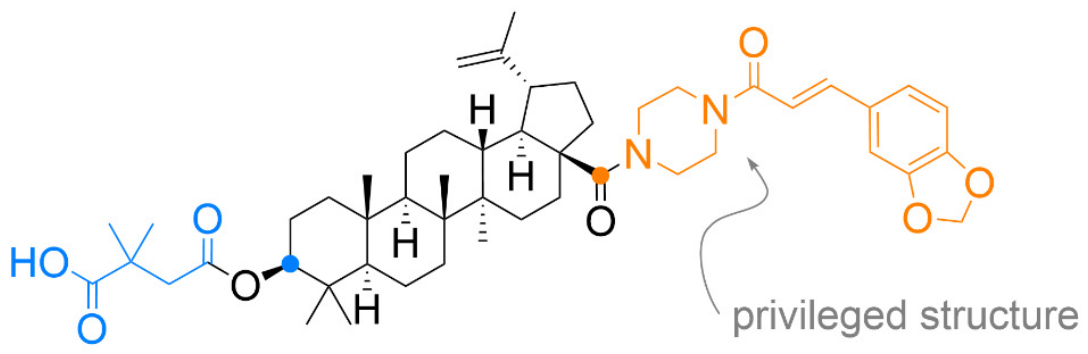

Figure 1. Chemical structure of betulinic acid and its derivatives.

BA has been shown to have anti-HIV-1 activity in the past. Although the test results were not groundbreaking, and the effect was observed only at relatively high concentrations [5] This discovery inevitably led to the synthesis of several other analogues. One of the derivatives with strong anti-HIV-1 activity was 3-O-(3,3-dimethylsuccinyl) betulinic acid, known as bevirimat (Figure 1, BT) [15]. BT acts as an inhibitor of HIV-1 particle maturation. Inhibition of viral particle maturation appears to be a critical point of therapeutic intervention. During the maturation phase, the viral protease cleaves the Gag polyprotein while releasing the individual structural proteins. The final step is the cleavage of p25 CA-SP1 to a functional p24 CA protein. Inhibition of the last step of maturation results in virus particles with aberrantly formed mature cores that are incapable of further infection [16]. BT advanced to the second phase of clinical testing [17-19], during which virus reduction was observed in only $40-50 \%$ of patients. The remainder of the patients developed resistance due to natural polymorphic variation in the Gag polyprotein [20]. With this result, the clinical studies were terminated.

Given the important features of BA mentioned above, it is no surprise that many research groups addressed it. Hundreds of derivatives have been prepared over the last few decades. However, with derivatization, for example, the expected effect disappeared, resistance developed rapidly, or toxicity to normal cells increased dramatically. For antiHIV derivatives, several so-called "privileged structures" (Figure 1), structural motifs that can be the basis for the design of an effective drug, were found [21,22]. BA is most often chemically modified at C-3 and C-28 positions. Addition to the double bond between carbon atoms C-20 and C-30 usually does not significantly enhance activity, on the contrary, the activity often disappears. This finding generally applies to both anti-cancer and antiHIV effects [23-25]. Recent works have confirmed that the presence of an extra amine 
group introduced by conjugation into a BA molecule can significantly increase antitumour potency $[26,27]$.

This work presents the preparation and biological evaluation of new analogues of BA and BT containing an amino group. In the past, fluorescent analogues of BA labelled with green-emitting BODIPY (4,4-difluoro-4-bora-3a,4a-diaza-s-indacene) $[28,29]$ and redemitting Rhodamine B [30] were synthesized to study its localization and trafficking in living cells. In this work, we synthesized and studied new derivatives of BA and BT labelled at C-3 and C-28 positions using a small blue-emitting BODIPY dye.

\section{Materials and Methods}

\subsection{Chemical Synthesis}

Aluminium silica gel sheets for detection in UV light (TLC Silica gel 60 F254, Merck, Darmstadt, Denmark) were used for thin-layer chromatography (TLC), subsequent visualization was proceeded by a diluted solution of sulfuric acid in methanol and plates were heated. Silica gel (30-60 $\mu \mathrm{m}$, SiliTech, MP Biomedicals, Costa Mesa, CA, USA) was used for column chromatography. NMR Spectra were recorded by Agilent-MR DDR2 (Santa Clara, CA, USA). HRMS were measured by LTQ ORBITRAP VELOS with HESI+/HESIionization (Thermo Scientific, Waltham, MA, USA). For microwave synthesis, an Initiator Classic 355,301 (Biotage, Uppsala, Sweden) was used.

The following chemicals were purchased from TCI Europe (Zwijndrecht, Belgium): $N, N, N$-triethylamine- $\mathrm{Et}_{3} \mathrm{~N}(>99 \%)$, 4-dimethylaminopyridine-4-DMAP (>99\%), 1-(3dimethylaminopropyl)-3-ethylcarbodiimide hydrochloride-EDCI (>98\%), $N, N^{\prime}$-dicyclohexylcarbodiimide-DCC (>98\%), 1-hydroxybenzotriazole monohydrate-HOBt (>97\%), triphenylphosphine- $\mathrm{PPh}_{3}(>95 \%), p$-toluenesulfonic acid monohydrate- $p$ - $\mathrm{TsOH}(>98 \%)$, and palladium on carbon-Pd/C (10\%). The following chemicals were purchased from Sigma-Aldrich (Prague, Czech Republic): 3-azidopropylamine ( $\geq 95 \%), 1-(2-N$-boc-aminoethyl)piperazine $(\geq 95 \%), \beta$-alanine $(99 \%)$. Betulinic acid (BA) was purchased from Betulinines (Stř́ibrná skalice, Czech Republic).

The solvents for column chromatography and reactions were purchased from PENTA (Praha, Czech Republic) and were used without further distillation.

Compound Synthesis and Characterization

8-N-(3-Azidopropyl)amino-4,4-difluoro-4-bora-3a,4a-diaza-s-indacene (BODIPY-N 3 )

To a solution of BODIPY-SMe (205 mg, $0.86 \mathrm{mmol})$ in DCM $(10 \mathrm{~mL})$, 3-azidopropylamine (95 $\mathrm{mg}, 0.95 \mathrm{mmol}$ ) was added and the mixture was stirred for $30 \mathrm{~min}$ at RT. The solvents were evaporated under reduced pressure and the residue was taken up with AcOEt and the product was precipitated by the addition of hexanes. BODIPY-N $3(243 \mathrm{mg}, 0.83 \mathrm{mmol})$ was obtained as a yellowish solid in $97 \%$ yield. $R_{F}=0.55$ in hexanes-AcOEt $1: 1 .{ }^{1} \mathrm{H}$ NMR (400 MHz, CD3OD) $\delta$ ppm: 2.11 (quin, $\mathrm{J}=6.7 \mathrm{~Hz}, 2 \mathrm{H}), 3.56(\mathrm{t}, \mathrm{J}=6.5 \mathrm{~Hz}, 2 \mathrm{H}), 3.87(\mathrm{t}$, $\mathrm{J}=7.4 \mathrm{~Hz}, 2 \mathrm{H}$ ), 6.39 (br. s., $1 \mathrm{H}), 6.55$ (br. s, $1 \mathrm{H}$ ), 7.32 (br. s, $1 \mathrm{H}$ ), 7.36 (br. s., $2 \mathrm{H}$ ), 7.57 (s, $1 \mathrm{H}) .{ }^{13} \mathrm{C}$ NMR $\left(101 \mathrm{MHz}, \mathrm{CD}_{3} \mathrm{OD}\right) \delta$ ppm: 27.00, 44.08, 48.76, 112.67, 113.99, 115.78, 123.16, 130.78, 133.76, 148.87. HRMS-ESI: calculated $290.12628 \mathrm{Da}$, found $m / z 291.13312[\mathrm{M}+\mathrm{H}]^{+}$. 8-N-(3-Aminopropyl)amino-4,4-difluoro-4-bora-3a,4a-diaza-s-indacene (BODIPY-NH $\left.\mathbf{~}_{2}\right)$

To a solution of BODIPY-N $3(150 \mathrm{mg}, 0.52 \mathrm{mmol})$ in AcOEt $(8 \mathrm{~mL})$, was added Pd/C $(80 \mathrm{mg}$ ) and the mixture was stirred under hydrogen atmosphere for $2 \mathrm{~h}$. The catalyst was filtered off and the solvents were evaporated under reduced pressure. The residue was taken up with AcOEt and the product was obtained after precipitation with hexane. BODIPY-NH $\mathbf{N H}_{2}(96 \mathrm{mg}, 0.36 \mathrm{mmol})$ was obtained as yellow solid in $70 \%$ yield. $\mathrm{R}_{\mathrm{F}}=0.15$ in DCM-MeOH 20:1 (v/v). ${ }^{1} \mathrm{H}$ NMR (400 MHz, CD $\left.\mathrm{CD}_{3} \mathrm{OD}\right) \delta$ ppm: 1.98 (quin, J = 6.7 Hz, $2 \mathrm{H}$ ), $2.87(\mathrm{t}, \mathrm{J}=6.7 \mathrm{~Hz}, 2 \mathrm{H}), 3.83(\mathrm{t}, \mathrm{J}=7.0 \mathrm{~Hz}, 2 \mathrm{H}), 6.37$ (br. s, $1 \mathrm{H}), 6.52$ (br. s, $1 \mathrm{H}), 7.27$ (br. s, $1 \mathrm{H}), 7.30-7.36(\mathrm{~m}, 2 \mathrm{H}), 7.55$ (br. s, $1 \mathrm{H}) .{ }^{13} \mathrm{C} \mathrm{NMR}\left(101 \mathrm{MHz}, \mathrm{CD}_{3} \mathrm{OD}\right) \delta$ ppm: 29.67, $39.12,45.50,112.53,113.78,115.51,123.15,130.40,133.46,148.73$. HRMS-ESI: calculated 264.13578 Da, found $m / z 263.12810[\mathrm{M}-\mathrm{H}]^{-}$.

8-N-( $\beta$-Alanyl)amino-4,4-difluoro-4-bora-3a,4a-diaza-s-indacene (BODIPY-CO $\left.\mathbf{C}_{2} \mathbf{H}\right)$ 
To a solution of BODIPY-SMe $(220 \mathrm{mg}, 0.92 \mathrm{mmol})$ in DMSO $(5 \mathrm{~mL})$, was added a solution of $\beta$-Ala $(91 \mathrm{mg}, 1.02 \mathrm{mmol})$ in $\mathrm{H}_{2} \mathrm{O}(2 \mathrm{~mL})$. The mixture was stirred at $30{ }^{\circ} \mathrm{C}$ for $16 \mathrm{~h}$. The solvents were removed under reduced pressure and the residue was diluted with $\mathrm{CHCl}_{3}(100 \mathrm{~mL})$. The product was precipitated by the addition of cyclohexane. BODIPY$\mathrm{CO}_{2} \mathrm{H}(175 \mathrm{mg}, 0.63 \mathrm{mmol})$ was obtained as yellow solids in $68 \%$ yield. $\mathrm{R}_{\mathrm{F}}=0.38$ in hexanes-AcOEt 1:1. ${ }^{1} \mathrm{H} \mathrm{NMR}\left(400 \mathrm{MHz}, \mathrm{CD}_{3} \mathrm{OD}\right) \delta \mathrm{ppm}: 2.87(\mathrm{t}, \mathrm{J}=6.9 \mathrm{~Hz}, 2 \mathrm{H}), 4.00(\mathrm{t}$, $\mathrm{J}=6.9 \mathrm{~Hz}, 2 \mathrm{H}), 6.35$ (br. s., $1 \mathrm{H}), 6.53$ (br. s., $1 \mathrm{H}), 7.27-7.31$ (m, $1 \mathrm{H}), 7.33$ (br. s., $2 \mathrm{H})$, 7.55 (br. s., $1 \mathrm{H}) .{ }^{13} \mathrm{C}$ NMR (101 MHz, CD $\left.3 \mathrm{OD}\right) \delta$ ppm: 31.71, 42.48, 112.67, 114.02, 115.89, 123.26, 130.78, 133.83, 148.75, 173.03. HRMS-ESI: calculated 279.09906 Da, found $\mathrm{m} / \mathrm{z}$ $278.09139[\mathrm{M}-\mathrm{H}]^{-}$.

(3ß)-N-(3-Azidopropyl)-3-hydroxylup-20(29)-ene-28-amide (1)

To a solution of BA (200 mg, $0.44 \mathrm{mmol})$ and 4-DMAP (59 mg, $0.48 \mathrm{mmol})$ in DMF (3 mL), 3-azidopropylamine (53 mg, $0.53 \mathrm{mmol}), \mathrm{HOBt}(65 \mathrm{mg}, 0.48 \mathrm{mmol})$ and EDCI (93 $\mathrm{mg}, 0.48 \mathrm{mmol}$ ) were sequentially added. The mixture was stirred at RT for $36 \mathrm{~h}$. Solvents were removed under reduced pressure and the residue was chromatographed twice (i. DCM-MeOH 100:1, v/v ii. DCM $\rightarrow$ DCM-MeOH 70:1, v/v). Azide 1 (200 mg, $0.37 \mathrm{mmol}$ ) was obtained as white solids in $84 \%$ yield. $\mathrm{R}_{\mathrm{F}}=0.48$ in DCM-MeOH 40:1 $(v / v) .{ }^{1} \mathrm{H}$ NMR $\left(400 \mathrm{MHz}, \mathrm{CDCl}_{3}\right) \delta$ ppm: 0.63-0.70 (m, $\left.1 \mathrm{H}\right), 0.75(\mathrm{~s}, 3 \mathrm{H}), 0.81(\mathrm{~s}, 3 \mathrm{H})$, 0.83-0.91 (m, 1 H), 0.93 (s, $3 \mathrm{H}), 0.96$ (s, $3 \mathrm{H}), 0.96$ (s, $3 \mathrm{H}), 0.97-1.05$ (m, $1 \mathrm{H}), 1.12-1.65$ (m, $19 \mathrm{H}), 1.67$ (s, $3 \mathrm{H}), 1.69-1.72(\mathrm{~m}, 1 \mathrm{H}), 1.75-1.82(\mathrm{~m}, 2 \mathrm{H}), 1.90-1.95(\mathrm{~m}, 1 \mathrm{H}), 2.38-2.48$ (m, $1 \mathrm{H}), 3.083 .20(\mathrm{~m}, 2 \mathrm{H}), 3.32(\mathrm{~s}, 4 \mathrm{H}), 4.58(\mathrm{~s}, 1 \mathrm{H}), 4.73(\mathrm{~s}, 1 \mathrm{H}), 5.85(\mathrm{t}, \mathrm{J}=5.9 \mathrm{~Hz}, 1 \mathrm{H})$; Figure S1. ${ }^{13} \mathrm{C}$ NMR $\left(101 \mathrm{MHz}, \mathrm{CDCl}_{3}\right) \delta$ ppm: 14.29, 15.01, 15.79, 15.80, 17.93, 19.13, 20.57, 25.26, 27.05, 27.63, 28.68, 29.10, 30.51, 33.40, 34.04, 36.61, 36.84, 37.40, 38.05, 38.36, 38.49, $40.40,42.11,46.38,49.31,49.74,50.27,55.02,55.30,78.58,109.01,150.50,175.96$; Figure S3. HRMS-ESI: calculated $538.42468 \mathrm{Da}$, found $\mathrm{m} / \mathrm{z} 561.41394[\mathrm{M}+\mathrm{Na}]^{+}$; Figure S2.

4-\{[(3ß)-28-[(3-Azidopropyl)amino]-28-oxolup-20(29)-ene-3-yl]oxy\}-2,2-dimethyl-4-oxobutanoic acid (2)

To a solution of 1 ( $200 \mathrm{mg}, 0.37 \mathrm{mmol})$ and 4-DMAP $(73 \mathrm{mg}, 0.59 \mathrm{mmol})$ in THF $(2 \mathrm{~mL})$, 2,2-dimethylsucccinic anhydride $(238 \mathrm{mg}, 1.86 \mathrm{mmol})$ and $p$ - $\mathrm{TsOH}$ were added and the mixture was stirred for $2 \mathrm{~h}$ at $130{ }^{\circ} \mathrm{C}$ in microwave reactor (MW). The mixture was diluted with $\mathrm{H}_{2} \mathrm{O}(20 \mathrm{~mL})$ and extracted with DCM $(4 \times 15 \mathrm{~mL})$. Combined organic layers were dried over $\mathrm{Na}_{2} \mathrm{SO}_{4}$, filtered and the solvents were evaporated under reduced pressure. The residue was chromatographed two times (i. DCM-MeOH 100:1, v/v; ii. hexanes-AcOEt 3:1, $v / v)$. Compound $2(94 \mathrm{mg}, 0.14 \mathrm{mmol})$ was obtained as white solids in $38 \%$ yield. $\mathrm{R}_{\mathrm{F}}=0.60$ in hexanes-AcOEt, 1:1. ${ }^{1} \mathrm{H}$ NMR $\left(400 \mathrm{MHz} \mathrm{CDCl}_{3}\right) \delta \mathrm{ppm}: 0.73-0.76(\mathrm{~m}, 1 \mathrm{H}), 0.79(\mathrm{~s}, 3 \mathrm{H})$, $0.82(\mathrm{~s}, 6 \mathrm{H}), 0.92(\mathrm{~s}, 3 \mathrm{H}), 0.95(\mathrm{~s}, 3 \mathrm{H}), 0.97-1.01(\mathrm{~m}, 1 \mathrm{H}), 1.121 .17(\mathrm{~m}, 1 \mathrm{H}), 1.27(\mathrm{~s}, 3 \mathrm{H})$, 1.29 (s, $3 \mathrm{H}), 1.30-1.67(\mathrm{~m}, 17 \mathrm{H}), 1.67(\mathrm{~s}, 3 \mathrm{H}), 1.71(\mathrm{~d}, \mathrm{~J}=7.0 \mathrm{~Hz}, 1 \mathrm{H}), 1.75-1.81(\mathrm{~m}, 2 \mathrm{H})$, 1.90-1.93 (m, $1 \mathrm{H}), 2.39-2.46(\mathrm{~m}, 1 \mathrm{H}), 2.52-2.68(\mathrm{~m}, 2 \mathrm{H}), 3.083 .14(\mathrm{~m}, 1 \mathrm{H}), 3.22-3.33(\mathrm{~m}$, $2 \mathrm{H}), 3.33-3.43(\mathrm{~m}, 4 \mathrm{H}), 4.45-4.50(\mathrm{~m}, 1 \mathrm{H}), 4.58(\mathrm{~s}, 1 \mathrm{H}), 4.73(\mathrm{~s}, 1 \mathrm{H}), 5.86(\mathrm{t}, \mathrm{J}=5.9 \mathrm{~Hz}$, $1 \mathrm{H})$; Figure S4. ${ }^{13} \mathrm{C}$ NMR (101 MHz, CDCl3) $\delta$ ppm: 14.60, 16.14, 16.46, 18.13, 19.44, 20.92, 23.59 , 24.99, 25.27, 25.55, 25.58, 27.88, 29.02, 29.42, 30.83, 33.73, 34.30, 36.97, 37.08, 37.70, $37.72,38.40,40.44,40.76,42.45,44.69,46.74,49.65,50.06,50.50,55.47,55.65,81.51,109.42$, 109.99, 150.81, 170.95, 176.38, 182.48; Figure S5. HRMS-ESI: calculated 666.47202 Da, found $m / z 667.47921[\mathrm{M}+\mathrm{H}]^{+}, 689.46125[\mathrm{M}+\mathrm{Na}]^{+}$and $705.43463[\mathrm{M}+\mathrm{K}]^{+}$; Figure S6.

(3ß)-N-(3-Aminopropyl)-3-hydroxylup-20(29)-ene-28-amide (3) [31]

A solution of $2(339 \mathrm{mg}, 0.63 \mathrm{mmol})$ and $\mathrm{PPh}_{3}(248 \mathrm{mg}, 0.95 \mathrm{mmol})$ in THF $(10 \mathrm{~mL})$ was stirred for $3 \mathrm{~h}$ at RT. Water $(1 \mathrm{~mL})$ was added and the mixture was stirred for additional $20 \mathrm{~h}$ at RT. Solvents were evaporated under reduced pressure and the residue was chromatographed $\left(\mathrm{CHCl}_{3}-\mathrm{MeOH} 20: 1, v / v+0.5 \% \mathrm{Et}_{3} \mathrm{~N} \rightarrow 10: 1, v / v+0.5 \% \mathrm{Et}_{3} \mathrm{~N}\right)$. Compound 3 (278 $\mathrm{mg}, 0.54 \mathrm{mmol}$ ) was obtained as white solids in $86 \%$ yield. $\mathrm{R}_{\mathrm{F}}=0.15$ in DCM-MeOH 10:1 $(v / v)+0.5 \% \mathrm{Et}_{3} \mathrm{~N} .{ }^{1} \mathrm{H}$ NMR $\left(400 \mathrm{MHz}, \mathrm{CD}_{3} \mathrm{OD}\right) \delta$ ppm: 0.70-0.75 (m, $\left.1 \mathrm{H}\right), 0.77$ (s, $3 \mathrm{H}), 0.88(\mathrm{~s}, 3 \mathrm{H}), 0.91-0.96(\mathrm{~m}, 1 \mathrm{H}), 0.97(\mathrm{~s}, 3 \mathrm{H}), 0.99(\mathrm{~s}, 3 \mathrm{H}), 1.02(\mathrm{~s}, 3 \mathrm{H}), 1.04-1.10$ (m, $1 \mathrm{H}), 1.15-1.69(\mathrm{~m}, 20 \mathrm{H}), 1.71(\mathrm{~s}, 3 \mathrm{H}), 1.80-1.95(\mathrm{~m}, 2 \mathrm{H}), 2.10-2.19(\mathrm{~m}, 1 \mathrm{H}), 2.55-2.64(\mathrm{~m}$, $1 \mathrm{H}), 2.69(\mathrm{t}, \mathrm{J}=6.9 \mathrm{~Hz}, 2 \mathrm{H}), 3.07-3.18(\mathrm{~m}, 2 \mathrm{H}), 3.20-3.32(\mathrm{~m}, 2 \mathrm{H}), 4.60(\mathrm{~s}, 1 \mathrm{H}), 4.72(\mathrm{~s}, 1 \mathrm{H})$; 
Figure S7. ${ }^{13} \mathrm{C}$ NMR (101 MHz, CD 3 OD) $\delta$ ppm: 13.80, 14.78, 15.46, 15.49, 18.07, 18.37, 20.78, $25.58,26.64,27.28,29.22,30.57,32.01,32.75,34.24,35.77,36.95,37.53,38.11,38.25,38.57$, $38.72,40.61,42.14,46.67,50.00,50.68,55.49,55.57,78.26,108.63,150.86,177.88$; Figure S8. HRMS-ESI: calculated 512.43418 Da, found $m / z 513.44206[\mathrm{M}+\mathrm{H}]^{+}$; Figure S9.

(3ß)-N-[N'-(4,4-Difluoro-4-bora-3a,4a-diaza-s-indacene-8-yl)-3-aminopropyl]-3-hydroxylup-20(29)-ene-28-amide (4)

To a solution of BA (50 mg, $0.11 \mathrm{mmol})$ and BODIPY-NH $\mathbf{N H}_{2}(32 \mathrm{mg}, 0.12 \mathrm{mmol})$ in DMF (3 mL), 4-DMAP (15 mg, $0.12 \mathrm{mmol}), \operatorname{HOBt}(16 \mathrm{mg}, 0.12 \mathrm{mmol})$ and EDCI (23 mg, $0.12 \mathrm{mmol})$ were added. The mixture was stirred for $20 \mathrm{~h}$ at RT. The solvents were evaporated under reduced pressure and residue was chromatographed (hexanes-AcOEt 1:1). Compound 4 (56 mg, $0.08 \mathrm{mmol}$ ) was obtained as yellow-green solid in $73 \%$ yield. $R_{\mathrm{F}}=0.27$ in hexanesAcOEt 1:1. ${ }^{1} \mathrm{H}$ NMR $\left(400 \mathrm{MHz}, \mathrm{CDCl}_{3}\right) \delta$ ppm: 0.66-0.70 (m, $\left.1 \mathrm{H}\right), 0.74(\mathrm{~s}, 3 \mathrm{H}), 0.80(\mathrm{~s}, 3 \mathrm{H})$, 0.84-0.89 (m, $1 \mathrm{H}), 0.90(\mathrm{~s}, 3 \mathrm{H}), 0.96(\mathrm{~s}, 3 \mathrm{H}), 1.00(\mathrm{~s}, 3 \mathrm{H}), 1.01-1.12(\mathrm{~m}, 1 \mathrm{H}), 1.17-1.71(\mathrm{~m}$, $20 \mathrm{H}), 1.72(\mathrm{~s}, 3 \mathrm{H}), 1.73-1.80(\mathrm{~m}, 2 \mathrm{H}), 1.87-2.04(\mathrm{~m}, 4 \mathrm{H}), 2.482 .55(\mathrm{~m}, 1 \mathrm{H}), 3.14-3.21$ $(\mathrm{m}, 2 \mathrm{H}), 3.28-3.36(\mathrm{~m}, 2 \mathrm{H}), 3.73(\mathrm{q}, \mathrm{J}=5.5 \mathrm{~Hz}, 2 \mathrm{H}), 4.65(\mathrm{~s}, 1 \mathrm{H}), 4.77(\mathrm{~s}, 1 \mathrm{H}), 6.27(\mathrm{t}$, $\mathrm{J}=5.9 \mathrm{~Hz}, 1 \mathrm{H}), 6.45$ (br. s., $1 \mathrm{H}), 6.50$ (br. s., $1 \mathrm{H}), 7.12$ (br. s, $1 \mathrm{H}), 7.51$ (br. s., $1 \mathrm{H}), 7.67$ (br. s., $2 \mathrm{H}), 9.73(\mathrm{t}, \mathrm{J}=5.3 \mathrm{~Hz}, 1 \mathrm{H})$; Figure S10. ${ }^{13} \mathrm{C} \mathrm{NMR}\left(101 \mathrm{MHz}, \mathrm{CDCl}_{3}\right) \delta \mathrm{ppm}: 14.67$, $15.35,16.12,16.15,18.25,19.46,20.96,25.61,27.38,27.96,29.15,29.53,30.88,33.53,34.34$, $36.75,37.17,37.94,38.48,38.72,38.84,40.81,42.48,44.48,46.90,50.10,50.58,55.35,55.72$, 78.95, 109.78, 113.37, 114.28, 116.74, 122.42, 125.66, 131.71, 134.28, 134.30, 149.07, 150.40, 179.08; Figure S11. HRMS-ESI: calculated 702.48556 Da, found $m / z 725.47504[\mathrm{M}+\mathrm{Na}]+$ and $741.44867[\mathrm{M}+\mathrm{K}]+$; Figure S12.

(3ß)-N-(3-Azidopropyl)-3-[N' -(4,4-difluoro-4-bora-3a,4a-diaza-s-indacene-8-yl)- $\beta$-alanyl]oxy-lup-20(29)-ene-28-amide (5)

To a solution of $\mathbf{1}(130 \mathrm{mg}, 0.24 \mathrm{mmol})$ and 4-DMAP (59 mg, $0.48 \mathrm{mmol})$ in dry DCM (5 mL), BODIPY-CO $\mathbf{C O}_{2} \mathbf{H}(101 \mathrm{mg}, 0.36 \mathrm{mmol})$ and DCC (100 mg, $\left.0.48 \mathrm{mmol}\right)$ were added. The mixture was stirred at RT for $16 \mathrm{~h}$. DCU was filtered off and the solvents were removed under reduced pressure. The crude was chromatographed (DCM-MeOH 100:1, v/v), and the material thus obtained was dissolved in AcOEt and precipitated by the addition of hexanes and chromatographed once again (DCM-MeOH 100:1, v/v) to obtain pure 5 $(160 \mathrm{mg}, 0.20 \mathrm{mmol})$ as yellow solid in 83\% yield. $\mathrm{R}_{\mathrm{F}}=0.62 \mathrm{in} \mathrm{DCM}-\mathrm{MeOH} 40: 1(v / v) .{ }^{1} \mathrm{H}$ NMR (400 MHz, $\left.\mathrm{CDCl}_{3}\right) \delta$ ppm: 0.78-0.82 (m, $\left.1 \mathrm{H}\right), 0.85$ (s, $\left.3 \mathrm{H}\right), 0.85(\mathrm{~s}, 6 \mathrm{H}), 0.94(\mathrm{~s}, 3 \mathrm{H})$, 0.97 (s, 3 H), 0.99-1.05 (m, $2 \mathrm{H}), 1.14-1.18(\mathrm{~m}, 1 \mathrm{H}), 1.22-1.66(\mathrm{~m}, 17 \mathrm{H}), 1.69(\mathrm{~s}, 3 \mathrm{H}), 1.72(\mathrm{~m}$, $1 \mathrm{H}), 1.75-1.81(\mathrm{~m}, 2 \mathrm{H}), 1.89-1.97(\mathrm{~m}, 1 \mathrm{H}), 2.42-2.50(\mathrm{~m}, 1 \mathrm{H}), 2.80(\mathrm{t}, \mathrm{J}=6.3 \mathrm{~Hz}, 2 \mathrm{H})$, 3.09-3.16 (m, 1 H), 3.23-3.39 (m, $4 \mathrm{H}), 3.94(\mathrm{q}, \mathrm{J}=6.1 \mathrm{~Hz}, 2 \mathrm{H}), 4.56-4.60(\mathrm{~m}, 1 \mathrm{H}), 4.60$ (s, $1 \mathrm{H}), 4.74(\mathrm{~s}, 1 \mathrm{H}), 5.83$ (t, J = $5.9 \mathrm{~Hz}, 1 \mathrm{H}), 6.44$ (br. s., $2 \mathrm{H}), 7.01$ (br. s., $2 \mathrm{H}), 7.45-7.68$ (m,

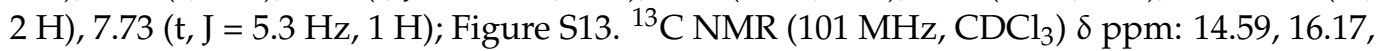
$16.19,16.54,18.14,19.47,20.96,23.73,25.54,28.06,29.04,29.43,30.85,32.63,33.74,34.27$, $36.98,37.11,37.70,37.87,38.33,38.39,40.77,42.48,42.53,46.74,55.42,55.65,76.70,77.02$, 77.34, 82.86, 109.44, 114.00, 114.79, 115.12, 123.08, 132.60, 135.52, 147.98, 150.82, 171.54, 176.32; Figure S14. HRMS-ESI: calculated $799.51318 \mathrm{Da}$, found $m / z 822.50287[\mathrm{M}+\mathrm{Na}]^{+}$and $838.47620[\mathrm{M}+\mathrm{K}]^{+}$; Figure S15.

(3ß)-N-(3-Aminopropyl)-3-[N'-(4,4-difluoro-4-bora-3a,4a-diaza-s-indacene-8-yl)- $\beta$-alanyl]oxy-lup-20(29)-ene-28-amide (6)

To a solution of $5(60 \mathrm{mg}, 0.08 \mathrm{mmol})$ in dry THF $(3 \mathrm{~mL}), \mathrm{PPh}_{3}(26 \mathrm{mg}, 0.10 \mathrm{mmol})$ was added. After stirring for $3 \mathrm{~h}, \mathrm{H}_{2} \mathrm{O}$ was added and the mixture was stirred for $20 \mathrm{~h}$. Solvents were removed under reduced pressure and the product was chromatographed $\left(\mathrm{DCM}-\mathrm{MeOH}\right.$ 9:1, v/v $\rightarrow$ MeOH-H ${ }_{2} \mathrm{O}$ 100:1, v/v) to obtain 6 (25 mg, $0.03 \mathrm{mmol}$ ) as yellow solids in 43\% yield. $\mathrm{R}_{\mathrm{F}}=0.12$ in DCM-MeOH 10:1 (v/v) + 0.5\% $\mathrm{Et}_{3} \mathrm{~N} .{ }^{1} \mathrm{H}$ NMR $(400 \mathrm{MHz}$, $\left.\mathrm{CDCl}_{3}\right) \delta$ ppm: 0.79-0.82 (m, $\left.1 \mathrm{H}\right), 0.85(\mathrm{~s}, 3 \mathrm{H}), 0.85(\mathrm{~s}, 6 \mathrm{H}), 0.95(\mathrm{~s}, 3 \mathrm{H}), 0.97(\mathrm{~s}, 3 \mathrm{H})$, 0.98-1.03 (m, $2 \mathrm{H}), 1.12-1.16(\mathrm{~m}, 1 \mathrm{H}), 1.26-1.65(\mathrm{~m}, 22 \mathrm{H}), 1.69$ (s, $3 \mathrm{H}), 1.72-1.77$ (m, $2 \mathrm{H})$, 1.92-1.98 (m, 1 H), 2.45-2.51 (m, $1 \mathrm{H}), 2.77-2.85$ (m, $4 \mathrm{H}), 3.11-3.18(\mathrm{~m}, 1 \mathrm{H}), 3.30-3.40$ (m, $2 \mathrm{H}), 3.98(\mathrm{t}, \mathrm{J}=6.3 \mathrm{~Hz}, 2 \mathrm{H}), 4.57-4.61(\mathrm{~m}, 2 \mathrm{H}), 4.74(\mathrm{~s}, 1 \mathrm{H}), 6.40(\mathrm{t}, \mathrm{J}=5.5 \mathrm{~Hz}, 1 \mathrm{H}), 6.46$ (br. s., $2 \mathrm{H}), 6.99-7.09(\mathrm{~m}, 2 \mathrm{H}), 7.49-7.72(\mathrm{~m}, 3 \mathrm{H})$; Figure S16. ${ }^{13} \mathrm{C}$ NMR $\left(101 \mathrm{MHz}, \mathrm{CDCl}_{3}\right)$ 
$\delta$ ppm: 14.59, 16.17, 16.19, 16.54, 18.14, 19.48, 20.97, 23.74, 25.56, 28.07, 29.43, 30.89, 32.44, $32.67,33.70,34.28,37.11,37.52,37.66,37.87,38.33,38.49,40.09,40.76,42.48,42.52,46.74$, $50.07,50.55,55.42,55.61,82.90,109.34,114.15,114.82,115.40,122.45,132.64,135.57,148.06$, 150.99, 171.58, 176.32; Figure S17. HRMS-ESI: monoisotopic mass $773.52268 \mathrm{Da}$, found $\mathrm{m} / \mathrm{z}$ $774.53046[\mathrm{M}+\mathrm{H}]^{+}$and $772.51587[\mathrm{M}-\mathrm{H}]^{-}$; Figure S18.

Tert-butyl-(3-\{[(3ß)-3-hydroxy-28-oxolup-20(29)-ene-28-yl]amino\}propyl)-carbamate (7) [23]

To a solution of BA $(1.00 \mathrm{~g}, 2.19 \mathrm{mmol})$ and 4-DMAP $(295 \mathrm{mg}, 2.41 \mathrm{mmol})$ in DMF (12 mL), N-boc-1,3-diaminopropane (459 mg, $2.63 \mathrm{mmol}), \mathrm{HOBt}(326 \mathrm{mg}, 2.41 \mathrm{mmol})$ and EDCI (462 mg, $2.41 \mathrm{mmol})$ were added. The mixture was stirred for $48 \mathrm{~h}$ at RT. The solvents were evaporated under reduced pressure and the residue was chromatographed (DCM-MeOH 100:1, v/v). Compound 7 (900 mg, $1.47 \mathrm{mmol})$ was obtained as white solid in $67 \%$ yield. $\mathrm{R}_{\mathrm{F}}=0.34$ in DCM-MeOH 40:1 (v/v). ${ }^{1} \mathrm{H} \mathrm{NMR}\left(400 \mathrm{MHz}, \mathrm{CDCl}_{3}\right) \delta \mathrm{ppm}$ : $0.650 .70(\mathrm{~m}, 1 \mathrm{H}), 0.75(\mathrm{~s}, 3 \mathrm{H}), 0.81(\mathrm{~s}, 3 \mathrm{H}), 0.85-0.90(\mathrm{~m}, 1 \mathrm{H}), 0.93(\mathrm{~s}, 3 \mathrm{H}), 0.96$ (s, $3 \mathrm{H}), 0.97(\mathrm{~s}, 3 \mathrm{H}), 0.98-1.05(\mathrm{~m}, 2 \mathrm{H}), 1.13-1.20(\mathrm{~m}, 1 \mathrm{H}), 1.22-1.44(\mathrm{~m}, 8 \mathrm{H}), 1.45(\mathrm{~s}, 9 \mathrm{H})$, $1.461 .68(\mathrm{~m}, 11 \mathrm{H}), 1.69(\mathrm{~s}, 3 \mathrm{H}), 1.69-1.81(\mathrm{~m}, 2 \mathrm{H}), 1.88-2.00(\mathrm{~m}, 1 \mathrm{H}), 2.00-2.07(\mathrm{~m}, 1 \mathrm{H})$, 2.42-2.50 (m, $1 \mathrm{H}), 3.10-3.28$ (m, $5 \mathrm{H}), 3.30-3.39$ (m, $1 \mathrm{H}), 4.59$ (s, $1 \mathrm{H}), 4.74$ (s, $1 \mathrm{H}), 4.91$ (br. s., $1 \mathrm{H}), 6.33$ (br. s., $1 \mathrm{H})$; Figure S19. $\left.{ }^{13} \mathrm{C} \mathrm{NMR} \mathrm{(101} \mathrm{MHz,} \mathrm{CDCl}_{3}\right) \delta$ ppm: 14.64, 15.35, 16.12, $16.14,18.28,19.48,20.94,25.64,27.41,27.97,28.40$ (s, 3 C) 29.48, 30.54, 30.92, 33.65, 34.39, $35.28,37.20,37.75,38.51,38.72,38.84,40.76,42.47,46.66,50.04,50.64,55.38,55.76,67.07$, 78.96, 79.32, 109.27, 151.05, 156.65, 176.50; Figure S20. HRMS-ESI: calculated 612.48661 Da, found $m / z 613.49394[\mathrm{M}+\mathrm{H}]^{+}, 635.47609[\mathrm{M}+\mathrm{Na}]^{+}$and $651.44943[\mathrm{M}+\mathrm{K}]^{+}$; Figure S21.

4-\{[(3ß)-28-(\{3-[(Tert-butoxycarbonyl)amino]propyl\}amino)-28-oxolup-20(29)-ene-3-yl]oxy\}2,2-dimethyl-4-oxobutanoic acid (8)

To a solution of $7(400 \mathrm{mg}, 0.65 \mathrm{mmol})$ and 4-DMAP $(128 \mathrm{mg}, 1.04 \mathrm{mmol})$ in THF $(4 \mathrm{~mL}), 2,2-$ dimethylsuccinic anhydride $(418 \mathrm{mg}, 3.26 \mathrm{mmol})$ and $p$ - $\mathrm{TsOH}$ were added. The mixture was stirred for $2 \mathrm{~h}$ at $130{ }^{\circ} \mathrm{C}$ in a microwave reactor. The mixture was poured into water and extracted with DCM $(4 \times 20 \mathrm{~mL})$. Combined organic layers were washed with $\mathrm{KHSO}_{4}(3 \times 5 \mathrm{~mL})$ and brine. The organic layer was dried over $\mathrm{Na}_{2} \mathrm{SO}_{4}$ and the solvents were evaporated under reduced pressure. The residue was chromatographed (DCM-MeOH 40:1, v/v + 1\% $\left.\mathrm{Et}_{3} \mathrm{~N}\right)$ to obtain $8(260 \mathrm{mg}, 0.35 \mathrm{mmol})$ as white solids in $54 \%$ yield. $\mathrm{R}_{\mathrm{F}}=0.18$ in DCM-MeOH 40:1 $(v / v)+1 \% \mathrm{Et}_{3} \mathrm{~N} .{ }^{1} \mathrm{H} \mathrm{NMR}\left(400 \mathrm{MHz}, \mathrm{CDCl}_{3}\right) \delta$ ppm: 0.74-0.77 (m, $1 \mathrm{H}), 0.80$ (s, $3 \mathrm{H}), 0.82$ (s, $6 \mathrm{H}), 0.92$ (s, $3 \mathrm{H}), 0.96$ (s, $3 \mathrm{H}), 0.97-1.02$ (m, $1 \mathrm{H}), 1.13-1.17(\mathrm{~m}, 1 \mathrm{H}), 1.25-1.27(\mathrm{~m}, 2 \mathrm{H}), 1.28(\mathrm{~s}, 3 \mathrm{H}), 1.30(\mathrm{~s}, 3 \mathrm{H}), 1.31-1.44(\mathrm{~m}, 7 \mathrm{H})$, $1.45(\mathrm{~s}, 9 \mathrm{H}), 1.46-1.68(\mathrm{~m}, 10 \mathrm{H}), 1.69(\mathrm{~s}, 3 \mathrm{H}), 1.70-1.82(\mathrm{~m}, 2 \mathrm{H}), 1.90-1.97(\mathrm{~m}, 1 \mathrm{H})$, $2.032 .07(\mathrm{~m}, 1 \mathrm{H}), 2.41-2.48(\mathrm{~m}, 1 \mathrm{H}), 2.53-2.70(\mathrm{~m}, 2 \mathrm{H}), 3.10-3.40(\mathrm{~m}, 7 \mathrm{H}), 4.46-4.51(\mathrm{~m}$, $1 \mathrm{H}), 4.59$ (s, $1 \mathrm{H}), 4.74$ (s, $1 \mathrm{H}), 4.94$ (br. s., $1 \mathrm{H}), 6.43$ (br. s., $1 \mathrm{H})$; Figure S22. ${ }^{13} \mathrm{C}$ NMR (101 MHz, $\left.\mathrm{CDCl}_{3}\right) \delta$ ppm: 14.61, 16.09, 16.15, 16.47, 18.14, 19.45, 20.95, 23.60, 25.02, 25.58, $25.61,27.90,28.39,29.46,30.49,30.88,33.61,34.30,35.35,37.08,37.70,37.92,38.40,38.52$, $40.44,40.72,40.76,42.46,44.71,46.64,49.99,50.52,55.47,55.80,79.40,81.55,109.37,150.97$, $156.80,171.00,176.72,182.24$; Figure S23. HRMS-ESI: calculated $740.53395 \mathrm{Da}$, found $\mathrm{m} / \mathrm{z}$ $741.54119[\mathrm{M}+\mathrm{H}]^{+}$and $763.52302[\mathrm{M}+\mathrm{Na}]^{+}$; Figure S24.

4-\{[(3ß)-28-[(3-Aminopropyl)amino]-28-oxolup-20(29)-ene-3-yl]oxy\}-2,2-dimethyl-4-oxobutanooic acid hydrochloride (9)

Compound 6 (130 mg, $0.18 \mathrm{mmol})$ was dissolved in $\mathrm{CHCl}_{3}(1.5 \mathrm{~mL})$ and $2 \mathrm{M} \mathrm{HCl}$ solution in $\mathrm{Et}_{2} \mathrm{O}(3 \mathrm{~mL})$ was added slowly. The mixture was stirred for $1 \mathrm{~h}$ at $\mathrm{RT}$ under argon atmosphere. Solvents were evaporated under reduced pressure and the residue was sonicated for $20 \mathrm{~min}$ in $\mathrm{Et}_{2} \mathrm{O}(5 \mathrm{~mL})$. The product was collected by filtration and dried in vacuo. Compound 9 (102 mg, $0.16 \mathrm{mmol})$ was obtained as white solids in $91 \%$ yield. $\mathrm{R}_{\mathrm{F}}=0.1$ in DCM-MeOH 9:1 (v/v). ${ }^{1} \mathrm{H}$ NMR (400 MHz, CD $\left.3 \mathrm{OD}\right) \delta$ ppm: 0.81-0.83 (m, $1 \mathrm{H}), 0.86(\mathrm{~s}, 6 \mathrm{H}), 0.88(\mathrm{~s}, 1 \mathrm{H}), 0.89(\mathrm{~s}, 3 \mathrm{H}), 0.98$ (s, $3 \mathrm{H}), 1.02(\mathrm{~s}, 3 \mathrm{H}), 1.03-1.11(\mathrm{~m}, 1 \mathrm{H})$, $1.19(\mathrm{~m}, 1 \mathrm{H}), 1.25(\mathrm{~s}, 3 \mathrm{H}), 1.26(\mathrm{~s}, 3 \mathrm{H}), 1.27-1.32(\mathrm{~m}, 1 \mathrm{H}), 1.36-1.65(\mathrm{~m}, 15 \mathrm{H}), 1.69(\mathrm{~s}, 3 \mathrm{H})$, 1.70-1.76 (m, $2 \mathrm{H}), 1.80-1.90(\mathrm{~m}, 5 \mathrm{H}), 2.10-2.15(\mathrm{~m}, 1 \mathrm{H}), 2.52-2.65(\mathrm{~m}, 3 \mathrm{H}), 2.902 .96$ (m, $2 \mathrm{H}), 3.06-3.13(\mathrm{~m}, 1 \mathrm{H}), 3.23-3.30(\mathrm{~m}, 2 \mathrm{H}), 4.43-4.48(\mathrm{~m}, 1 \mathrm{H}), 4.59$ (s, $1 \mathrm{H}), 4.70(\mathrm{~s}, 1 \mathrm{H})$, $7.89(\mathrm{t}, \mathrm{J}=5.9 \mathrm{~Hz}, 1 \mathrm{H})$; Figure S25. ${ }^{13} \mathrm{C}$ NMR (101 MHz, CD $\mathrm{CDD}_{3} \delta \mathrm{ppm:} \mathrm{13.64,} \mathrm{15.36,} \mathrm{15.43,}$ 
$15.66,17.85,18.13,20.76,23.25,24.43,24.79,25.49,27.06,27.71,29.22,30.51,32.59,34.06$, 35.22 , 36.85, 36.86, 37.42, 37.58, 38.02, 38.03, 38.18, 39.94, 40.60, 42.13, 44.23, 49.90, 50.50, $55.46,55.65,81.22,108.66,150.77,171.53,179.14,179.17$; Figure S26. HRMS-ESI: calculated 640.48152 Da, found $m / z 641.48955[\mathrm{M}+\mathrm{H}]^{+}$; Figure S27.

4-\{[(3ß)-28-\{[N-(4,4-Difluoro-4-bora-3a,4a-diaza-s-indacene-8-yl)-3-aminopropyl]amino\}28-oxolup-20(29)-ene-3-yl]oxy\}-2,2-dimethyl-4-oxobutanoic acid (10)

Compound 9 (15 mg, $0.02 \mathrm{mmol})$ and BODIPY-SMe $(6 \mathrm{mg}, 0.03 \mathrm{mmol})$ were dissolved in the mixture of $\mathrm{CHCl}_{3}(2 \mathrm{~mL})$ and THF $(1 \mathrm{~mL})$. To this solution, one drop of $\mathrm{Et}_{3} \mathrm{~N}$ was added. The mixture was stirred $30 \mathrm{~min}$ at RT. Solvents were evaporated under reduced pressure and the residue was chromatographed (DCM-MeOH 19:1, v/v+1\% Et ${ }_{3} \mathrm{~N}$ ). The mixture was dissolved in AcOEt and washed with $\mathrm{KHSO}_{4}(10 \%$ solution, $3 \times 5 \mathrm{~mL})$ and brine $(1 \times 5 \mathrm{~mL})$. Organic layer was dried over $\mathrm{Na}_{2} \mathrm{SO}_{4}$ and the solvents were evaporated. Compound 10 (14 mg, $0.02 \mathrm{mmol})$ as yellow-green solid in $74 \%$ yield. $\mathrm{R}_{\mathrm{F}}=0.73$ in DCM$\mathrm{MeOH}$ 9:1 (v/v). ${ }^{1} \mathrm{H}$ NMR $\left(400 \mathrm{MHz}, \mathrm{CDCl}_{3}\right) \delta \mathrm{ppm}: 0.73-0.77(\mathrm{~m}, 1 \mathrm{H}), 0.78(\mathrm{~s}, 3 \mathrm{H})$, $0.81(\mathrm{~s}, 3 \mathrm{H}), 0.82(\mathrm{~s}, 3 \mathrm{H}), 0.83-0.85(\mathrm{~m}, 1 \mathrm{H}), 0.89$ (s, $3 \mathrm{H}), 0.99$ (s, 3 H), 1.00-1.10 (m, $1 \mathrm{H})$, $1.16-1.21(\mathrm{~m}, 1 \mathrm{H}), 1.29(\mathrm{~s}, 3 \mathrm{H}), 1.31(\mathrm{~s}, 3 \mathrm{H}), 1.34-1.67(\mathrm{~m}, 15 \mathrm{H}), 1.72(\mathrm{~s}, 3 \mathrm{H}), 1.741 .79(\mathrm{~m}$, $2 \mathrm{H}), 1.87-2.03(\mathrm{~m}, 5 \mathrm{H}), 2.49-2.71(\mathrm{~m}, 3 \mathrm{H}), 3.14-3.20(\mathrm{~m}, 1 \mathrm{H}), 3.33(\mathrm{q}, \mathrm{J}=5.4 \mathrm{~Hz}, 2 \mathrm{H})$, $3.74(\mathrm{q}, \mathrm{J}=5.5 \mathrm{~Hz}, 2 \mathrm{H}), 4.46-4.51(\mathrm{~m}, 1 \mathrm{H}), 4.65(\mathrm{~s}, 1 \mathrm{H}), 4.77(\mathrm{~s}, 1 \mathrm{H}), 6.24(\mathrm{t}, \mathrm{J}=6.1 \mathrm{~Hz}, 1 \mathrm{H})$, 6.44 (br. s., 1 H), 6.51 (br. s., 1 H), 7.12 (br. s., 1 H), 7.51 (br. s., 1 H), 7.68 (br. s., 2 H), 9.71 (t, $\mathrm{J}=5.5 \mathrm{~Hz}, 1 \mathrm{H})$; Figure S28. ${ }^{13} \mathrm{C} \mathrm{NMR}\left(101 \mathrm{MHz}, \mathrm{CDCl}_{3}\right) \delta \mathrm{ppm}: 14.63,16.11,16.15,16.47$, 18.09 , 19.43, 20.99, 23.59, 24.97, 25.62, 27.88, 29.16, 29.51, 30.86, 33.56, 34.26, 36.73, 37.06, $37.70,37.89$, 38.40, 38.49, 40.45, 40.81, 42.47, 44.40, 44.70, 46.88, 50.08, 50.47, 55.46, 55.71, $81.51,109.83,113.40,114.28,116.67,122.36,125.65,131.78,134.36,149.06,150.35,171.00$, 179.13, 182.28; Figure S29. HRMS-APCI: calculated $830.53291 \mathrm{Da}$, found $m / z 829.52699$ $[\mathrm{M}-\mathrm{H}]^{-}$; Figure S30.

(3ß)-28-(4-\{2-[(Tert-butoxycarbonyl)amino]ethyl\}piperazine-1-yl)-28-oxolup-20(29)-ene3-yl acetate (12)

To a solution of compound $11(1.27 \mathrm{~g}, 2.55 \mathrm{mmol})$ in DCM (20 mL), oxalyl chloride $(1.2 \mathrm{~mL})$ in DCM $(10 \mathrm{~mL})$ and 3 drops of DMF were added. After stirring for $2 \mathrm{~h}$ at RT, the solvents were co-evaporated with toluene $(3 \times 20 \mathrm{~mL})$. Chloride thus obtained was dissolved in DCM (35 mL), and 1-(2-N-boc-aminoethyl)piperazine (876 mg, $3.82 \mathrm{mmol})$ followed by $\mathrm{Et}_{3} \mathrm{~N}(0.42 \mathrm{~mL})$ were added. After stirring for $16 \mathrm{~h}$ at RT, the mixture was diluted with DCM $(20 \mathrm{~mL})$ and washed with brine $(3 \times 30 \mathrm{~mL})$. The organic layer was dried over $\mathrm{Na}_{2} \mathrm{SO}_{4}$ and the solvents were evaporated under reduced pressure. The residue was chromatographed $\left(\mathrm{CHCl}_{3}-\mathrm{MeOH} 100: 1 \rightarrow 50: 1, v / v\right)$ to obtain product $12(720 \mathrm{mg}$, $1.01 \mathrm{mmol})$ as white solids in $40 \%$ yield. $\mathrm{R}_{\mathrm{F}}=0.16$ in DCM-MeOH 100:1 (v/v). ${ }^{1} \mathrm{H} \mathrm{NMR}$ (400 MHz, $\left.\mathrm{CDCl}_{3}\right) \delta$ ppm: 0.77-0.80 (m, $\left.1 \mathrm{H}\right), 0.83(\mathrm{~s}, 3 \mathrm{H}), 0.84(\mathrm{~s}, 3 \mathrm{H}), 0.85$ (s, $\left.3 \mathrm{H}\right), 0.94$ (s, $3 \mathrm{H}), 0.95(\mathrm{~s}, 3 \mathrm{H}), 0.97-1.00(\mathrm{~m}, 1 \mathrm{H}), 1.12-1.17(\mathrm{~m}, 1 \mathrm{H}), 1.28-1.42(\mathrm{~m}, 9 \mathrm{H}), 1.46(\mathrm{~s}, 9 \mathrm{H})$, $1.48-1.66(\mathrm{~m}, 7 \mathrm{H}), 1.68(\mathrm{~s}, 3 \mathrm{H}), 1.70-1.74(\mathrm{~m}, 1 \mathrm{H}), 1.81-1.87(\mathrm{~m}, 1 \mathrm{H}), 1.93-1.98(\mathrm{~m}, 1 \mathrm{H})$, 2.04 (s, 3 H), 2.07-2.11 (m, 1 H), 2.42 (br. s., 4 H), 2.49 (br. s., 2 H), 2.83-2.90 (m, 1 H), 2.94-3.01 (m, 1 H), 3.25 (br. s., 2 H), 3.61 (br. s., 4 H), 4.44-4.49 (m, $1 \mathrm{H}), 4.58$ (s, $1 \mathrm{H}), 4.72$ (s, $1 \mathrm{H}), 4.98$ (br. s., $1 \mathrm{H})$; Figure S31. ${ }^{13} \mathrm{C} \mathrm{NMR}\left(101 \mathrm{MHz}, \mathrm{CDCl}_{3}\right) \delta \mathrm{ppm}: 14.62,16.11,16.24$, $16.46,18.18,19.63,21.15,21.30,23.70,25.61,27.93,28.41,29.79,31.30,32.46,32.49,34.31$, $35.91,36.86,36.95,37.14,37.80,38.41,40.68,41.85,45.65,50.76,52.65,53.12,54.52,55.52$, 57.15, 79.30, 80.97, 109.16, 151.30, 155.90, 170.99, 173.46; Figure S32. HRMS-ESI: calculated $709.53937 \mathrm{Da}$, found $m / z 710.54562[\mathrm{M}+\mathrm{H}]^{+}$and $732.52546[\mathrm{M}+\mathrm{Na}]^{+}$; Figure S33.

Tert-butyl-(2-\{4-[(3ß)-3-hydroxy-28-oxolup-20(29)-ene-28-yl]piperazine-1-yl\}ethyl)carbamate (13)

To compound 12 (700 mg, $0.99 \mathrm{mmol})$ in $\mathrm{MeOH}(18 \mathrm{~mL})$ and THF $(9 \mathrm{~mL}), 4 \mathrm{M} \mathrm{NaOH}$ solution $(9 \mathrm{~mL})$ was added. The mixture was stirred for $2 \mathrm{~h}$ at RT. The mixture was neutralized by $1 \mathrm{M} \mathrm{HCl}$ solution and extracted with DCM $(4 \times 40 \mathrm{~mL})$. Combined organic layers were washed with saturated brine $(2 \times 50 \mathrm{~mL})$ and dried over $\mathrm{Na}_{2} \mathrm{SO}_{4}$. Solvents were evaporated under reduced pressure and the residue was chromatographed (DCM$\mathrm{MeOH} 40: 1, v / v)$ to obtain $13(310 \mathrm{mg}, 0.46 \mathrm{mmol})$ as white solids in $47 \%$ yield. $R_{\mathrm{F}}=0.33 \mathrm{in}$ 
DCM-MeOH 20:1 (v/v). ${ }^{1} \mathrm{H}$ NMR $\left(400 \mathrm{MHz} \mathrm{CDCl}_{3}\right) \delta$ ppm: 0.66-0.69 (m, $\left.1 \mathrm{H}\right), 0.75$ (s, $\left.3 \mathrm{H}\right)$, $0.82(\mathrm{~s}, 3 \mathrm{H}), 0.86-0.90(\mathrm{~m}, 1 \mathrm{H}), 0.93$ (s, $3 \mathrm{H}), 0.96$ (br. s, $6 \mathrm{H}), 1.12-1.17(\mathrm{~m}, 1 \mathrm{H}), 1.23-1.29$ $(\mathrm{m}, 2 \mathrm{H}), 1.29-1.42(\mathrm{~m}, 8 \mathrm{H}), 1.45(\mathrm{~s}, 9 \mathrm{H}), 1.48-1.66(\mathrm{~m}, 7 \mathrm{H}), 1.68(\mathrm{~s}, 3 \mathrm{H}), 1.69-1.73(\mathrm{~m}$, $1 \mathrm{H}), 1.81-1.87$ (m, $1 \mathrm{H}), 1.93-1.98(\mathrm{~m}, 1 \mathrm{H}), 2.06-2.11$ (m, $1 \mathrm{H}), 2.42$ (br. s., $4 \mathrm{H}), 2.48$ (br. s., $2 \mathrm{H}), 2.84-2.90$ (m, $1 \mathrm{H}), 2.94-3.00$ (m, $1 \mathrm{H}), 3.15-3.20$ (m, $1 \mathrm{H}), 3.25$ (br. s, $2 \mathrm{H}), 3.61$ (br. s., $4 \mathrm{H}), 4.57$ (s, $1 \mathrm{H}), 4.72$ (s, $1 \mathrm{H}), 4.99$ (br. s., $1 \mathrm{H})$; Figure S34. ${ }^{13} \mathrm{C} \mathrm{NMR}\left(101 \mathrm{MHz}, \mathrm{CDCl}_{3}\right)$

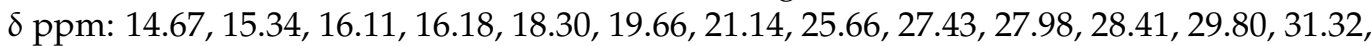
$32.48,32.50,34.39,35.91,36.88,36.97,37.23,38.74,38.85,40.67,41.87,45.62,50.86,52.67$, 53.11, 54.53, 55.47, 57.15, 78.97, 79.28, 109.10, 151.33, 155.91, 173.45; Figure S35. HRMS-ESI: calculated $667.52881 \mathrm{Da}$, found $m / z 668.53693[\mathrm{M}+\mathrm{H}]^{+}$; Figure S36.

(3ß)-28-[4-(2-Aminoethyl)piperazine-1-yl]-3-hydroxylup-20(29)-ene-28-one hydrochloride (14)

To compound $13(200 \mathrm{mg}, 0.30 \mathrm{mmol})$ in $\mathrm{CHCl}_{3}(2.8 \mathrm{~mL}), 2 \mathrm{M} \mathrm{HCl}$ solution in $\mathrm{Et}_{2} \mathrm{O}$ $(5.1 \mathrm{~mL})$ was slowly added. The mixture was stirred for $16 \mathrm{~h}$ at RT under argon. Solvents were removed under reduced pressure and the crude was sonicated for $20 \mathrm{~min}_{\text {in }} \mathrm{Et}_{2} \mathrm{O}$ $(5 \mathrm{~mL})$, collected by filtration and dried. Compound $14(142 \mathrm{mg}, 0.25 \mathrm{mmol})$ was isolated as white solid in $84 \%$ yield. ${ }^{1} \mathrm{H}$ NMR $\left(400 \mathrm{MHz}, \mathrm{CD}_{3} \mathrm{OD}\right) \delta \mathrm{ppm}$ : 0.69-0.73 (m, $\left.1 \mathrm{H}\right)$, $0.75(\mathrm{~s}, 3 \mathrm{H}), 0.86(\mathrm{~s}, 3 \mathrm{H}), 0.88-0.93(\mathrm{~m}, 1 \mathrm{H}), 0.95(\mathrm{~s}, 3 \mathrm{H}), 0.96(\mathrm{~s}, 3 \mathrm{H}), 1.01(\mathrm{~s}, 3 \mathrm{H})$, 1.02-1.07 (m, $1 \mathrm{H}), 1.22-1.67(\mathrm{~m}, 18 \mathrm{H}), 1.70(\mathrm{~s}, 3 \mathrm{H}), 1.73-1.77(\mathrm{~m}, 1 \mathrm{H}), 1.82-1.88(\mathrm{~m}, 1 \mathrm{H})$, 1.97-2.02 (m, $1 \mathrm{H}), 2.11-2.15$ (m, $1 \mathrm{H}), 2.79-2.86$ (m, $1 \mathrm{H}), 2.89-2.95(\mathrm{~m}, 1 \mathrm{H}), 3.11-3.15$ (m, $1 \mathrm{H}), 3.35-3.81(\mathrm{~m}, 11 \mathrm{H}), 4.59(\mathrm{~s}, 1 \mathrm{H}), 4.70(\mathrm{~s}, 1 \mathrm{H})$; Figure S37. ${ }^{13} \mathrm{C} \mathrm{NMR}(101 \mathrm{MHz}$, $\left.\mathrm{CD}_{3} \mathrm{OD}\right) \delta$ ppm: 13.65, 14.68, 15.27, 15.38, 18.04, 18.29, 20.86, 25.52, 26.63, 26.67, 27.18, 29.66, $30.92,31.88,33.62,33.63,34.19,36.94,36.96,38.53,38.68,40.54,41.64,45.78,50.78,52.19$, 52.37, 53.15, 54.58, 55.52, 78.24, 108.66, 150.85, 174.45; Figure S38. HRMS-ESI: calculated $567.47638 \mathrm{Da}$, found $m / z 568.4832[\mathrm{M}+\mathrm{H}]^{+}$; Figure S39.

(3ß)-28-\{4-[N-(4,4-Difluoro-4-bora-3a,4a-diaza-s-indacene-8-yl)-2-aminoethyl]piperazine1-yl\}-3-hydroxylup-20(29)-ene-28-one (15)

To compound $14(45 \mathrm{mg}, 0.08 \mathrm{mmol})$ and BODIPY-SMe $(21 \mathrm{mg}, 0.09 \mathrm{mmol})$ in the mixture of DCM $(5 \mathrm{~mL})$ and THF $(2.5 \mathrm{~mL})$, was added one drop of $\mathrm{Et}_{3} \mathrm{~N}$ and the mixture was stirred $30 \mathrm{~min}$ at RT. Solvents were evaporated under reduced pressure and the residue was chromatographed (DCM-MeOH 100:1, v/v) to obtain 15 (42 mg, $0.06 \mathrm{mmol}$ ) as yellow solids in 70\% yield. $\mathrm{R}_{\mathrm{F}}=0.19$ in DCM-MeOH 100:1 $(v / v) .{ }^{1} \mathrm{H} \mathrm{NMR}\left(400 \mathrm{MHz}, \mathrm{CDCl}_{3}\right) \delta$ ppm: 0.67-0.71 (m, 1 H), $0.76(\mathrm{~s}, 3 \mathrm{H}), 0.83$ (s, $3 \mathrm{H}), 0.87-0.91(\mathrm{~m}, 1 \mathrm{H}), 0.95(\mathrm{~s}, 3 \mathrm{H}), 0.97$ (s, $6 \mathrm{H}), 1.16-1.21(\mathrm{~m}, 1 \mathrm{H}), 1.21-1.32(\mathrm{~m}, 3 \mathrm{H}), 1.38-1.66(\mathrm{~m}, 15 \mathrm{H}), 1.69(\mathrm{~s}, 3 \mathrm{H}), 1.72-1.76(\mathrm{~m}$, $1 \mathrm{H}), 1.82-1.89$ (m, $1 \mathrm{H}), 1.93-1.98$ (m, $1 \mathrm{H}), 2.06-2.12$ (m, $1 \mathrm{H}), 2.55$ (br. s., $4 \mathrm{H}), 2.82-2.90$ (m, 3 H), 2.95-3.01 (m, 1 H), 3.17-3.21 (m, 1 H), 3.70 (br. s., 4 H), 3.75 (br. s., 2 H), 4.60 (s, $1 \mathrm{H}), 4.74$ (s, $1 \mathrm{H}), 6.41$ (br. s., $1 \mathrm{H}), 6.53$ (br. s., $1 \mathrm{H}), 6.91$ (br. s., $1 \mathrm{H}), 7.13$ (br. s., $1 \mathrm{H}), 7.51$ (br. s., $1 \mathrm{H}$ ), 7.72 (br. s., $1 \mathrm{H}), 7.92$ (br. s., $1 \mathrm{H})$; Figure S40. ${ }^{13} \mathrm{C}$ NMR $\left(101 \mathrm{MHz}, \mathrm{CDCl}_{3}\right)$

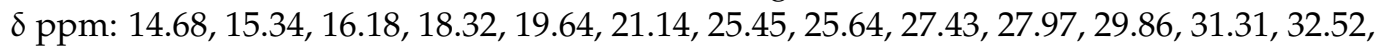
$34.42,35.93,36.92,37.24,38.74,38.86,40.69,41.80,41.90,45.62,50.84,52.53,52.65,54.26$, 54.60, 55.46, 78.98, 109.29, 113.76, 114.93, 122.67, 123.28, 125.04, 132.47, 135.78, 147.77, 151.12, 173.64; Figure S41. HRMS-ESI: calculated 757.52776 Da, found $m / z 780.5171[\mathrm{M}+\mathrm{Na}]^{+}$and $796.4904[\mathrm{M}+\mathrm{K}]^{+}$; Figure S42.

4-\{[(3ß)-28-(4-\{2-[(Tert-butoxycarbonyl)amino]ethyl\}piperazine-1-yl)-28-oxolup-20(29)ene-3-yl]oxy\}-2,2-dimethyl-4-oxobutanoic acid (16)

To a solution of 13 (500 mg, $0.75 \mathrm{mmol})$ and 4-DMAP (146 mg, $1.20 \mathrm{mmol})$ in THF $(5 \mathrm{~mL}), 2,2-$ dimethylsuccinic anhydride $(480 \mathrm{mg}, 3.74 \mathrm{mmol})$ and a catalytic amount of $p$-TsOH were added. The reaction was stirred for $2 \mathrm{~h}$ at $130{ }^{\circ} \mathrm{C}$ in a microwave reactor. The mixture was diluted with $\mathrm{H}_{2} \mathrm{O}$ and extracted with DCM $(4 \times 20 \mathrm{~mL})$. Combined organic layers were dried over $\mathrm{Na}_{2} \mathrm{SO}_{4}$ and the solvents were removed under reduced pressure. The crude was chromatographed twice (i. toluene-AcOEt 1:1 $\rightarrow$ AcOEt; ii. toluene-AcOEt $\left.1: 1+1 \% \mathrm{Et}_{3} \mathrm{~N} \rightarrow \mathrm{AcOEt} \rightarrow \mathrm{DCM}-\mathrm{MeOH} 9: 1, v / v\right)$. Compound 16 (328 mg, $\left.0.41 \mathrm{mmol}\right)$ was obtained as white solids in 53\% yield. $R_{F}=0.43$ in DCM-MeOH 9:1 (v/v). ${ }^{1} \mathrm{H}$ NMR (400 MHz, $\left.\mathrm{CDCl}_{3}\right) \delta$ ppm: 0.74-0.77 (m, $\left.1 \mathrm{H}\right), 0.81$ (s, $\left.6 \mathrm{H}\right), 0.83$ (s, $\left.3 \mathrm{H}\right), 0.93$ (s, $\left.3 \mathrm{H}\right), 0.95$ (s, 
$3 \mathrm{H}), 1.12-1.16(\mathrm{~m}, 1 \mathrm{H}), 1.27$ (br. s., $6 \mathrm{H}), 1.32-1.41(\mathrm{~m}, 8 \mathrm{H}), 1.44(\mathrm{~s}, 9 \mathrm{H}), 1.47-1.65$ (m, $7 \mathrm{H}), 1.68(\mathrm{~s}, 3 \mathrm{H}), 1.70-1.74(\mathrm{~m}, 1 \mathrm{H}), 1.80-1.86(\mathrm{~m}, 1 \mathrm{H}), 1.90-1.95(\mathrm{~m}, 1 \mathrm{H}), 2.05-2.09$ (m, $1 \mathrm{H}), 2.49-2.69$ (m, $6 \mathrm{H}), 2.82-2.89(\mathrm{~m}, 1 \mathrm{H}), 2.93-3.00$ (m, $1 \mathrm{H}), 3.29$ (br. s., $2 \mathrm{H}), 3.61$ (br. s., 4 H), 3.71 (br. s., 2 H), 4.45-4.50 (m, 1 H), 4.58 (s, 1 H), 4.72 (s, 1 H), 5.15 (br. s., $1 \mathrm{H})$; Figure S43. ${ }^{13} \mathrm{C}$ NMR $\left(101 \mathrm{MHz}, \mathrm{CDCl}_{3}\right) \delta$ ppm: 14.67, 16.06, 16.21, 16.57, 18.23, 19.64, 21.14, $23.66,23.68,25.57,25.58,25.92,25.94,27.91,28.40,29.82,31.30,32.36,32.39,34.26,35.96$, $36.69,36.82,37.12,37.76,38.39,38.41,40.63,41.87,45.60,50.72,52.60,52.94,54.49,55.53$, 57.19, 57.20, 109.24, 128.19, 129.00, 151.20, 155.99, 173.43; Figure S44. HRMS-ESI: calculated $795.57615 \mathrm{Da}$, found $m / z 796.58292[\mathrm{M}+\mathrm{H}]^{+}$; Figure S45.

4-\{[(3ß)-28-[4-(2-Aminoethyl)piperazine-1-yl]-28-oxolup-20(29)-ene-3-yl]oxy\}-2,2dimethyl-4-oxobutanoic acid hydrochloride (17)

To compound $16(150 \mathrm{mg}, 0.19 \mathrm{mmol})$ in $\mathrm{CHCl}_{3}(2 \mathrm{~mL}), 2 \mathrm{M} \mathrm{HCl}$ solution in $\mathrm{Et}_{2} \mathrm{O}$ $(3.2 \mathrm{~mL})$ was added. The mixture was stirred for $2 \mathrm{~h}$ at RT under argon atmosphere. Solvents were evaporated and the crude was sonicated for $20 \mathrm{~min}$ in $\mathrm{Et}_{2} \mathrm{O}(5 \mathrm{~mL})$. The precipitate was collected and dried in vacuo. Compound $17(102 \mathrm{mg}, 0.16 \mathrm{mmol})$ was obtained as white solids in $91 \%$ yield. ${ }^{1} \mathrm{H}$ NMR $\left(400 \mathrm{MHz}, \mathrm{CD}_{3} \mathrm{OD}\right) \delta \mathrm{ppm}: 0.82-0.85(\mathrm{~m}$, $1 \mathrm{H}), 0.87$ (br. s, $6 \mathrm{H}), 0.91$ (s, $3 \mathrm{H}), 0.98(\mathrm{~s}, 3 \mathrm{H}), 0.99-1.02(\mathrm{~m}, 1 \mathrm{H}), 1.04$ (s, $3 \mathrm{H}), 1.05-1.10$ (m, $1 \mathrm{H}), 1.27(\mathrm{~s}, 3 \mathrm{H}), 1.28(\mathrm{~s}, 3 \mathrm{H}), 1.29-1.69(\mathrm{~m}, 8 \mathrm{H}), 1.71(\mathrm{~s}, 3 \mathrm{H}), 1.73-1.78(\mathrm{~m}, 2 \mathrm{H})$, 1.83-1.89 (m, $1 \mathrm{H}), 1.98-2.04(\mathrm{~m}, 1 \mathrm{H}), 2.13-2.18$ (m, $1 \mathrm{H}), 2.54-2.67$ (m, $2 \mathrm{H}), 2.81-2.87$ (m, $1 \mathrm{H}), 2.91-2.97(\mathrm{~m}, 1 \mathrm{H}), 3.05-3.77(\mathrm{~m}, 11 \mathrm{H}), 4.45-4.49(\mathrm{~m}, 1 \mathrm{H}), 4.61(\mathrm{~s}, 1 \mathrm{H}), 4.72(\mathrm{~s}, 1 \mathrm{H})$; Figure S46. ${ }^{13} \mathrm{C}$ NMR (101 MHz, CD $\left.\mathrm{OD}\right) \delta$ ppm: 13.72, 15.25, 15.40, 15.67, 17.87, 18.29, $20.87,20.90,23.27,24.44,24.79,25.43,25.45,27.09,29.66,30.91,31.85,33.65,34.06,36.89$, $36.92,37.44,38.21,39.94,40.54,41.67,44.24,45.78,50.65,52.19,52.32,53.16,54.56,55.52$, 81.25, 108.69, 150.83, 171.53, 174.40, 179.15; Figure S47. HRMS-ESI: calculated $695.52372 \mathrm{Da}$, found $m / z 696.53153[\mathrm{M}+\mathrm{H}]^{+}$; Figure S48.

4-\{[(3ß)-28-\{4-[N-(4,4-Difluoro-4-bora-3a,4a-diaza-s-indacene-8-yl)-2-aminoethyl]piperazine-1-yl\}-28-oxolup-20(29)-ene-3-yl]oxy\}-2,2-dimethyl-4-oxobutanoic acid (18)

To compound 17 (50 mg, $0.07 \mathrm{mmol})$ and BODIPY-SMe $(19 \mathrm{mg}, 0.08 \mathrm{mmol})$ in the mixture of $\mathrm{CHCl}_{3}(5 \mathrm{~mL})$ and THF $(3 \mathrm{~mL})$, a drop of $\mathrm{Et}_{3} \mathrm{~N}$ was added. The mixture was stirred $30 \mathrm{~min}$ at RT. Solvents were evaporated and the residuum was chromatographed (DCM-MeOH 20:1, v/v + 0.5\% Et $\left.{ }_{3} \mathrm{~N}\right)$. Compound 18 (39 mg, $0.04 \mathrm{mmol}$ ) was obtained as yellowish solid in 62\% yield. $\mathrm{R}_{\mathrm{F}}=0.22$ in DCM-MeOH 20:1 $(v / v)+0.5 \% \mathrm{Et}_{3} \mathrm{~N} .{ }^{1} \mathrm{H}$ NMR (400 MHz, $\left.\mathrm{CDCl}_{3}\right) \delta$ ppm: 0.75-0.78 (m, $\left.1 \mathrm{H}\right), 0.81(\mathrm{~s}, 3 \mathrm{H}), 0.83(\mathrm{~s}, 3 \mathrm{H}), 0.84(\mathrm{~s}, 3 \mathrm{H})$, $0.880 .92(\mathrm{~m}, 1 \mathrm{H}), 0.94(\mathrm{~s}, 3 \mathrm{H}), 0.96(\mathrm{~s}, 3 \mathrm{H}), 1.15-1.19(\mathrm{~m}, 1 \mathrm{H}), 1.28(\mathrm{~s}, 3 \mathrm{H}), 1.30(\mathrm{~s}, 3 \mathrm{H})$, $1.351 .42(\mathrm{~m}, 7 \mathrm{H}), 1.45-1.51(\mathrm{~m}, 2 \mathrm{H}), 1.51-1.64(\mathrm{~m}, 6 \mathrm{H}), 1.69(\mathrm{~s}, 3 \mathrm{H}), 1.72-1.76(\mathrm{~m}, 1 \mathrm{H})$, $1.831 .89(\mathrm{~m}, 1 \mathrm{H}), 1.93-1.98(\mathrm{~m}, 1 \mathrm{H}), 2.06-2.12(\mathrm{~m}, 1 \mathrm{H}), 2.51-2.70(\mathrm{~m}, 6 \mathrm{H}), 2.82-2.89(\mathrm{~m}$, $3 \mathrm{H}), 2.94-3.00$ (m, $1 \mathrm{H}), 3.68$ (br. s., $4 \mathrm{H}), 3.75$ (br. s., $2 \mathrm{H}), 4.46-4.51$ (m, $1 \mathrm{H}), 4.59$ (s, $1 \mathrm{H})$, 4.73 (s, 1 H), 6.39 (br. s., 1 H), 6.52 (br. s., 1 H), 6.91 (br. s., 1 H), 7.13 (br. s., 1 H), 7.50 (br. s., $1 \mathrm{H}), 7.71$ (br. s., $1 \mathrm{H}), 7.96$ (br. s., $1 \mathrm{H})$; Figure S49. ${ }^{13} \mathrm{C} \mathrm{NMR}\left(101 \mathrm{MHz}, \mathrm{CDCl}_{3}\right) \delta \mathrm{ppm}$ : $14.67,16.13,16.21,16.50,18.18,19.60,21.17,23.65,25.05,25.60,27.92,29.68,29.84,31.29$, $32.49,34.32,35.94,36.88,37.12,37.74,38.42,40.48,40.68,41.88,41.96,44.75,45.65,50.71$, $52.57,52.61,54.28,54.57,55.55,81.47,109.33,113.68,114.87,122.61,123.38,125.04,132.41$, 135.68, 147.79, 151.11, 171.11, 173.64, 182.29; Figure S50. HRMS-ESI: calculated 885.57511 Da, found $m / z 884.56855[\mathrm{M}-\mathrm{H}]^{-}{ }^{-}$Figure S51.

\subsection{Biochemistry \\ 2.2.1. Cell Lines}

All cells (if not indicated otherwise) were purchased from the American Tissue Culture Collection (ATCC; Manassas, VA, USA). The highly chemosensitive CCRF-CEM line is derived from $\mathrm{T}$ lymphoblastic leukaemia, K562 represent cells of chronic myelogenous leukaemia. Colorectal adenocarcinoma HCT116 cell line and its p53 gene knockout counterpart (HCT116p53-/-, Horizon Discovery Ltd., Cambridge, UK) were used as models to assess the impact of p53 deficiency on cell line sensitivity. A549 cells are derived from lung adenocarcinoma and U2OS from human osteosarcoma. CEM-DNR and K562-Tax 
are well-characterized daunorubicin and paclitaxel-resistant sublines of CCRF-CEM and K562. The CEM-DNR resistant cells overexpress the P-glycoprotein and LRP protein, the K562-Tax overexpress P-glycoprotein but is losing the expression of LRP, which is present at parental K562 cell line. P-glycoprotein belongs to the ABC transporters' family and is involved in the primary and acquired multidrug resistance phenomenon by the efflux of toxic compounds, LRP protein is involved in the lysosomal degradation. MRC-5 and BJ cell lines were used as a non-tumour control and represent human fibroblasts. The cells were maintained in Nunc/Corning $80 \mathrm{~cm}^{2}$ plastic tissue culture flasks and cultured in cell culture medium according to ATCC or Horizon recommendations (DMEM/RPMI 1640 with $5 \mathrm{~g} / \mathrm{L}$-glucose, $2 \mathrm{mM}$ glutamine, $100 \mathrm{U} / \mathrm{mL}$ penicillin, $100 \mathrm{mg} / \mathrm{mL}$ streptomycin, $10 \%$ fetal calf serum, and $\mathrm{NaHCO}_{3}$ ).

\subsubsection{MTS Assay}

To perform the cytotoxicity MTS assay, cell suspensions were prepared and diluted according to the cell type and the expected target cell density $(25,000-35,000$ cells $/ \mathrm{mL})$ based on cell growth characteristics. Cells were added by an automatic pipettor $(30 \mu \mathrm{L})$ into 384 well microtiter plates. All tested compounds were dissolved in 100\% DMSO and four-fold dilutions of the intended test concentration were added in $0.15 \mu \mathrm{L}$ aliquots at time zero to the microtiter plate wells by the echo-acoustic liquid handler Echo550 (Labcyte, San Jose, CA, USA). The experiments were performed in technical duplicates and at least three biological replicates. The cells were incubated with the tested compounds for $72 \mathrm{~h}$ at $37^{\circ} \mathrm{C}$, in a $5 \% \mathrm{CO}_{2}$ atmosphere at $99 \%$ humidity. At the end of the incubation period, the cells were assayed by using the MTS test. Aliquots $(5 \mu \mathrm{L})$ of the MTS stock solution were pipetted into each well and incubated for an additional 1-4 h. After this incubation period, the optical density (OD) was measured at $490 \mathrm{~nm}$ with an Envision microplate reader (Perkin Elmer, Waltham, Massachusetts, USA). Tumour cell survival (TCS) was calculated using the following equation: $\mathrm{TCS}=\left(\mathrm{OD}_{\text {drug-exposed well }} / \mathrm{mean} \mathrm{OD}_{\text {control wells }}\right)$ $\times 100 \%$. The $\mathrm{IC}_{50}$ value, the drug concentration that is lethal to $50 \%$ of the tumour cells, was calculated from the appropriate dose-response curves in Dotmatics software (The Old Monastery, Windhill, Bishop's Stortford, Herts, UK).

\subsubsection{Cell Cycle and Apoptosis Analysis}

CCRF-CEM cells were seeded in 6-well plates at a density of $1 \times 106 /$ well. After $24 \mathrm{~h}$, compounds at concentrations corresponding to $1 \times$ or $5 \times \mathrm{IC}_{50}$ were added to the wells and incubated for $24 \mathrm{~h}$. Cells were then harvested, washed with cold $1 \times$ PBS and fixed in ice-cold $70 \%$ ethanol. Fixed cells were incubated overnight at $-20^{\circ} \mathrm{C}$, washed in hypotonic citrate buffer, treated with RNase $\left(50 \mu \mathrm{g} \mathrm{mL}^{-1}\right)$ and incubated with propidium iodide for $15 \mathrm{~min}$. DNA content was analysed using Becton Dickinson flow cytometer and cell cycle data were analysed in the program ModFitLT (Verity, Carrollton, TX, USA). Apoptosis was measured in a logarithmic model expressing the percentage of the particles with propidium content lower than cells in G0/G1 phase $(<\mathrm{G} 1)$ of the cell cycle. The mitotic marker pH3Ser10 antibody (Sigma) and secondary anti-mouse-FITC antibody (Sigma) were used for labelling and subsequent flow cytometry analysis of ethanol-fixed CCRF-CEM cells.

\subsubsection{BrDU Incorporation Analysis}

Cells were cultivated as in the method above and pulse-labelled with $10 \mu \mathrm{M}$ 5-bromo2-deoxyuridine (BrDU) for $30 \mathrm{~min}$ before collection to the test tubes. The cells were washed with cold $1 \times$ PBS and fixed in ice-cold $70 \%$ ethanol. Before analysis, they were washed with $1 \times$ PBS and incubated in $2 \mathrm{M} \mathrm{HCl}$ for $30 \mathrm{~min}$ at room temperature. Following neutralization with $0.1 \mathrm{M} \mathrm{Na}_{2} \mathrm{~B}_{4} \mathrm{O}_{7}$ (borax), the cells were washed with $0.5 \%$ Tween-20 and $1 \%$ BSA in $1 \times$ PBS. The cell pellets were stained using a primary anti-BrdU antibody (Exbio, Vestec, Czech Republic) for $30 \mathrm{~min}$ at room temperature and a secondary anti-mouse-FITC antibody (Sigma). The samples were then incubated with propidium iodide $\left(0.1 \mathrm{mg} \mathrm{mL}^{-1}\right)$, 
treated with RNase A $\left(0.5 \mathrm{mg} \mathrm{mL}^{-1}\right)$ for $1 \mathrm{~h}$ at room temperature in the dark and analysed as above.

\subsubsection{BrU Incorporation Analysis}

Cells were cultured, treated as above, pulse-labelled with $1 \mathrm{mM}$ 5-bromouridine (BrU) for 30 min and fixed in 1\% buffered paraformaldehyde with $0.05 \%$ NP-40 at room temperature for $15 \mathrm{~min}$. Following overnight incubation at $4{ }^{\circ} \mathrm{C}$, they were washed with $1 \%$ glycine in $1 \times$ PBS, washed with $1 \times$ PBS again and stained with primary anti-BrdU antibody cross-reacting to $\mathrm{BrU}$ (Exbio) for $30 \mathrm{~min}$ and secondary anti-mouse-FITC antibody (Sigma). The analysis was performed similarly to the BrDU analysis.

\subsubsection{Fluorescent Microscopy}

U2OS cell line (ATCC, USA) was transduced with premade lentiviral particles (VectalisTaKaRa, Japan) with sequences that express fluorescent protein tag mCherry targeted to specific subcellular locations. All cell lines were prepared according to the vendor's instructions. The U2OS-Nuc cell line was prepared by using rLV.EF1.mCherry-Nuc-9 (cat. n. 0023VCT), containing a NLS sequence that imports protein into the nucleus. The U2OS-ER cell line was transduced by rLV.EF1.mCherry-ER-9 (cat. n. 0025VCT), which contains a calreticulin signal sequence and a KDEL sequence that associates protein with the endoplasmic reticulum. The U2OS-GA cell line was transduced by rLV.EF1.mCherryGolgi-9 (cat. n. 0022VCT), containing a human GT precursor, a protein localized in Golgi Apparatus. The U2OS-Mito cell line was prepared by using rLV.EF1.mCherry-Mito-9 (cat. n. 0024VCT), containing a mitochondrial targeting sequence.

U2OS cells with fluorescent fusion proteins (density $1.0 \times 103$ per well) were seeded into 384 CellCarrier plates (Perkin Elmer, Waltham, MA, USA) and pre-incubated for $24 \mathrm{~h}$ at $37{ }^{\circ} \mathrm{C}$ and $5 \% \mathrm{CO}_{2}$. The attached cells were treated with tested compounds in concentration $10 \mu \mathrm{M}$ for $1 \mathrm{~h}$ and subsequently rinsed with fresh media. The live-cell imaging was performed by Cell Voyager CV7000 (Yokogawa, Tokyo, Japan) spinning disc confocal microscopy system at $37^{\circ} \mathrm{C}$ in a $5 \% \mathrm{CO}_{2}$ atmosphere. Live cells were monitored by a $60 \times$ water immersion objective. The fluorescent signal was excited by lasers $(405 \mathrm{~nm}$ and $561 \mathrm{~nm}$ ) and the emission was filtered by bandpass filters (BP 445/45 and BP 595/20). All images were post-processed, and Pearson's and Mander's coefficients were calculated using the JACoP plugin in Image-J software.

\subsubsection{VSV-G Pseudotyped HIV-1 Particles Production}

HIV-1 particles were obtained from HEK 293 cells, cotransfected by a combination of three vectors: packaging psPAX2 vector encoding HIV Gag, Pol, Tat and Rev, reporter/transfer $\mathrm{pWPXLd-GFP}$ vector encoding LTR, RRE and GFP as a reporter, and envelope pHEF-VSV-G vector, encoding vesicular stomatitis virus Env, VSV-G. The psPAX2 vector [32] was kindly provided by Dr. Luban, the pWPXLd-GFP and pHEF-VSV-G vectors were purchased from Addgene (Watertown, MA, USA).

HEK-293 cells were grown in Dulbecco's Modified Eagle Medium (DMEM, Sigma) supplemented with $10 \%$ fetal bovine serum (Sigma) and $1 \%$ L-glutamine (Sigma) at $37^{\circ} \mathrm{C}$ under $5 \% \mathrm{CO}_{2}$. A day before transfection, cells were plated at $3 \times 105$ cells per well. The following day, cells were transfected with the appropriate vectors using polyethylenimine (PEI, $1 \mathrm{mg} / \mathrm{mL}$ ) at a 2:1 PEI:DNA ratio. Four hours post-transfection, the culture medium was replaced with fresh DMEM, containing various concentrations of tested compounds, solubilized in DMSO. At $48 \mathrm{~h}$ post-transfection, the culture media containing released virions were harvested, filtered through $0.45-\mu \mathrm{m}$ pores membrane and used for immunochemical quantification and characterization by ELISA and Western blot using rabbit anti-HIV-1 CA antibody. 


\subsubsection{Single-Round Infectivity Assay}

The infectivity was determined similarly as described earlier [33-35]. Briefly, $48 \mathrm{~h}$ post-transfection, the culture media from HEK 293 cells transfected with psPAX2, pWPXLdGFP and pHEF-VSV-G vectors at a ratio 1:1:1 in the presence of tested compounds were collected and filtered through a $0.45-\mu \mathrm{m}$ filter. HIV-1 CA content was determined by ELISA [33]. The freshly seeded HEK 293 cells were infected with ELISA-normalized amounts of VSV-G pseudotyped HIV-1 particles and incubated for $48 \mathrm{~h}$. The cells were fixed with $2 \%$ paraformaldehyde and transferred to a FACS tube. Quantification of GFPpositive cells was performed using a BD FACS Aria III flow cytometer (BD Life Sciences, San Jose, CA, USA).

\subsubsection{Western Blot}

At $48 \mathrm{~h}$ post-transfection, $100 \mu \mathrm{L}$ aliquots of virus-containing culture media were combined with $20 \mu \mathrm{L}$ of PLB $(6 \times)$ and the samples were analysed by Western blot using rabbit anti-HIV-1 CA (in house production). Proteins were resolved by reducing SDS-PAGE $(12 \%)$ and blotted onto a nitrocellulose membrane. The antigen-antibody complexes were detected by Clarity ${ }^{\mathrm{TM}}$ Western ECL Substrate (Biorad, Hercules, CA, USA) and visualized using the FUSION 7S system (Vilber Lourmat, Marne-la-Vallée, France).

\section{Results and Discussion}

\subsection{Chemistry}

The synthesis of fluorescent labels was based on 8-thiomethyl BODIPY (BODIPY-SMe; Figure 2), which was prepared in our laboratory, according to the procedure previously described in the literature [36]. The thiomethyl group is reactive towards amines. After this reaction, secondary amines are formed with significant fluorescence characterized by emission in the blue region of the spectrum. For the preparation of betulinic acid conjugates, a carboxy-terminated derivative (BODIPY- $\mathbf{C O}_{2} \mathbf{H}$, Figure 2) was prepared by reaction of BODIPY-SMe and $\beta$-alanine [37] and an amino-terminated derivative by reaction with 3-azidopropan-1-amine [38] and reduction of azide (BODIPY-N $\mathbf{N}_{3}$, Figure 2) to amine (BODIPY-NH $\mathbf{N}_{2}$, Figure 2) by catalytic hydrogenation.

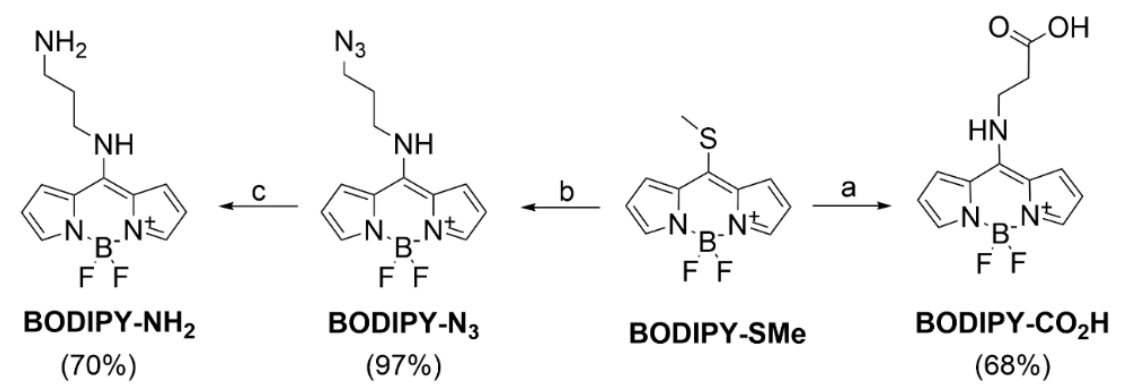

Figure 2. Synthesis of functionalized BODIPY dyes. Reagents and conditions: (a) $\beta$-Ala, DMSO- $\mathrm{H}_{2} \mathrm{O}$, $30{ }^{\circ} \mathrm{C}, 12 \mathrm{~h}$; (b) 3-azidopropylamine, DCM, $30 \mathrm{~min}, \mathrm{RT}$; (c) $\mathrm{H}_{2}, \mathrm{Pd} / \mathrm{C}, \mathrm{AcOEt}, 2 \mathrm{~h}, \mathrm{RT}$.

Betulinoyl azidopropylamide ( $N$-(3-azidopropyl)-3ß-hydroxylup-20(29)-en-28-amide) 1 was prepared by reacting BA with 3-azidopropan-1-amine using carbodiimide chemistry (Figure 3A). The reaction was catalysed by EDCI (1-ethyl-3-(3-dimethylaminopropyl)carbodiimide) in the presence of 4-DMAP (4-dimethylaminopyridine) and HOBt (1-hydroxybenzotriazole). The bevirimat derivative 2 was prepared from compound 1 by reaction with 2,2-dimethylsuccinic anhydride according to a protocol reported in the literature [39]. By Staudinger reduction [40] catalysed by triphenylphosphine in aqueous THF, the azido group of compound 1 was reduced to amino derivative 3 . In an effort to reduce derivative 2 by the same method, a non-separable mixture of products was obtained. By the reaction of BA with BODIPY- $\mathrm{NH}_{2}$ catalysed by DCC $\left(N, N^{\prime}\right.$-dicyclohexylcarbodiimide) in the presence of 4-DMAP, derivative 4 was obtained. This reaction proceeded without difficulty in good 
yield (Figure 3A). Azide 1 was further conjugated at the C-3 position with $\mathbf{B O D I P Y}-\mathrm{CO}_{2} \mathrm{H}$ by Steglich esterification [41] to produce derivative 5 . The azide group of derivative $\mathbf{5}$ was reduced by Staudinger reduction to amine 6 . When attempting to modify compound 4 with dimethylsuccinic anhydride under the conditions used to prepare derivative 2, degradation of the fluorescent label occurred, probably due to too high a temperature. Therefore, another synthetic procedure using a tert-butoxycarbonyl protecting group (Boc) on the terminal amino group was chosen for the synthesis of other "aminopropyl" derivatives (Figure 3B). The $N$-Boc-1,3-diaminopropane linker was conjugated to BA to give compound 7 , which could already be used to prepare the bevirimat derivative 8 . The protecting group was removed in an acidic environment to give amine 9. From compound 9, a fluorescently labelled derivative of bevirimat was prepared by the reaction with BODIPY-SMe.
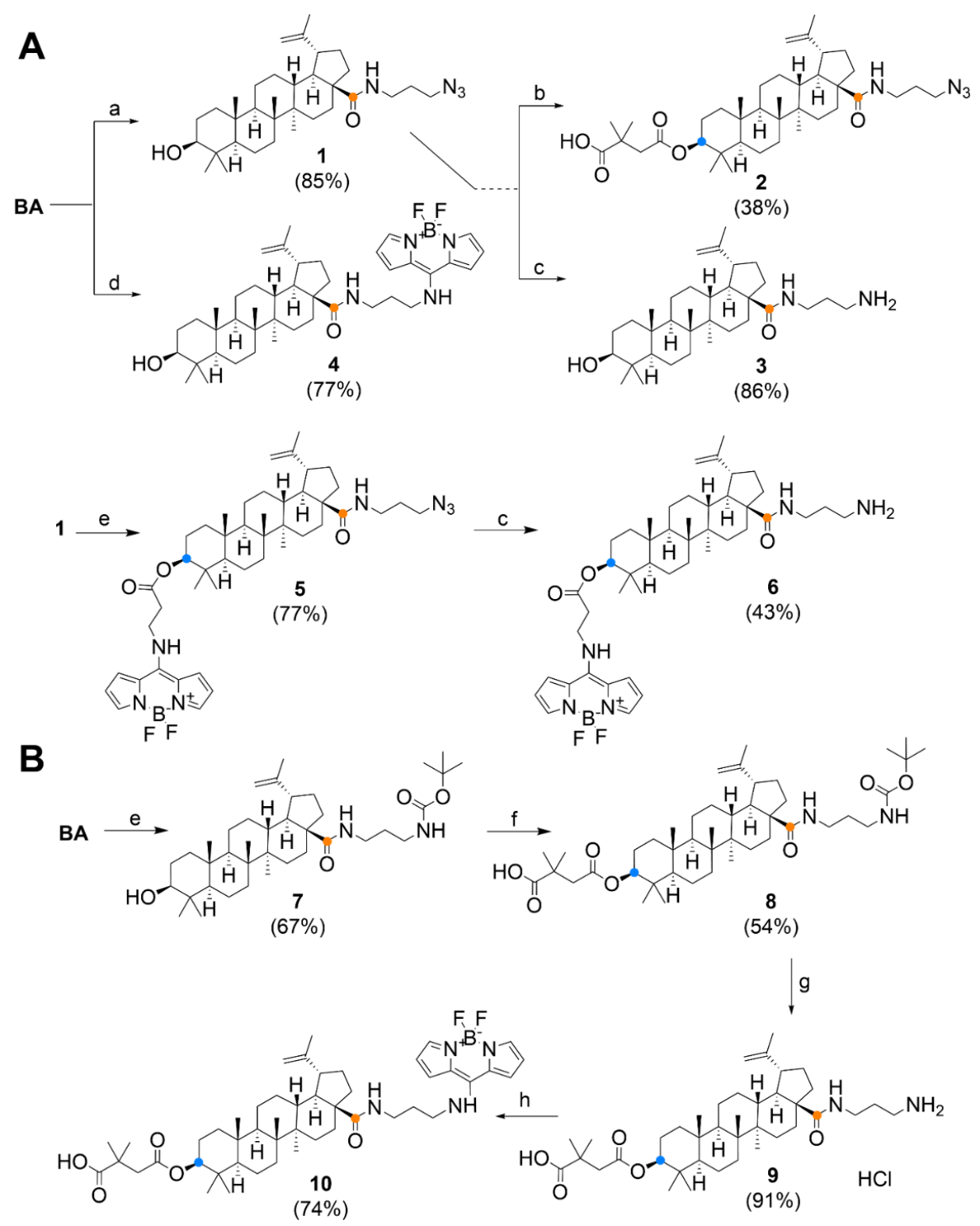

Figure 3. Synthesis of "aminopropyl" derivatives by azide reduction (panel A) and Boc chemistry (panel B). Reagents and conditions: (a) 3-azidopropylamine, 4-DMAP, HOBt, EDC, DMF, 36 h, RT; (b) 2,2-dimethylsuccinic anhydride, 4-DMAP, $p$ TsOH, THF, $2 \mathrm{~h}$, MW- $130^{\circ} \mathrm{C}$; (c) $\mathrm{PPh}_{3}, \mathrm{THF} / \mathrm{H}_{2} \mathrm{O}, 23 \mathrm{~h}$; (d) BODIPY-NH $\mathrm{N}_{2}$, 4-DMAP, DCC, DCM, 12 h, RT; (e) BODIPY-CO ${ }_{2} \mathrm{H}$, DCC, 4-DMAP, DCM, 12 h, RT; (f) N-Boc-1,3-diaminopropane, EDC, HOBt, 4-DMAP, DMF, 48 h, RT; (g) 2M HCl/Et $2 \mathrm{O}, 12$ h, RT (under argon); (h) BODIPY-SMe, $\mathrm{CHCl}_{3}-\mathrm{THF}, \mathrm{Et}_{3} \mathrm{~N}, 30 \mathrm{~min}, \mathrm{RT}$. 
Analogous to the synthetic procedure shown in Figure 3B, a series of substances with a piperazine linker at position C-28 was prepared (Figure 4). The introduction of the piperazine motif was chosen on the basis of promising results for the so-called privileged structures published previously [21]. The exception was that the C-3 hydroxyl was first acetylated to produce compound 11, and in the next step, the carboxyl group was activated to reactive chloride. After condensation with $1-(2-\mathrm{N}$-Boc-aminoethyl) piperazine, tertiary amide 12 was obtained. Deacetylation of $\mathbf{1 2}$ occurred in a relatively low yield; however, part of the starting material was recovered during the separation of the reaction mixture.

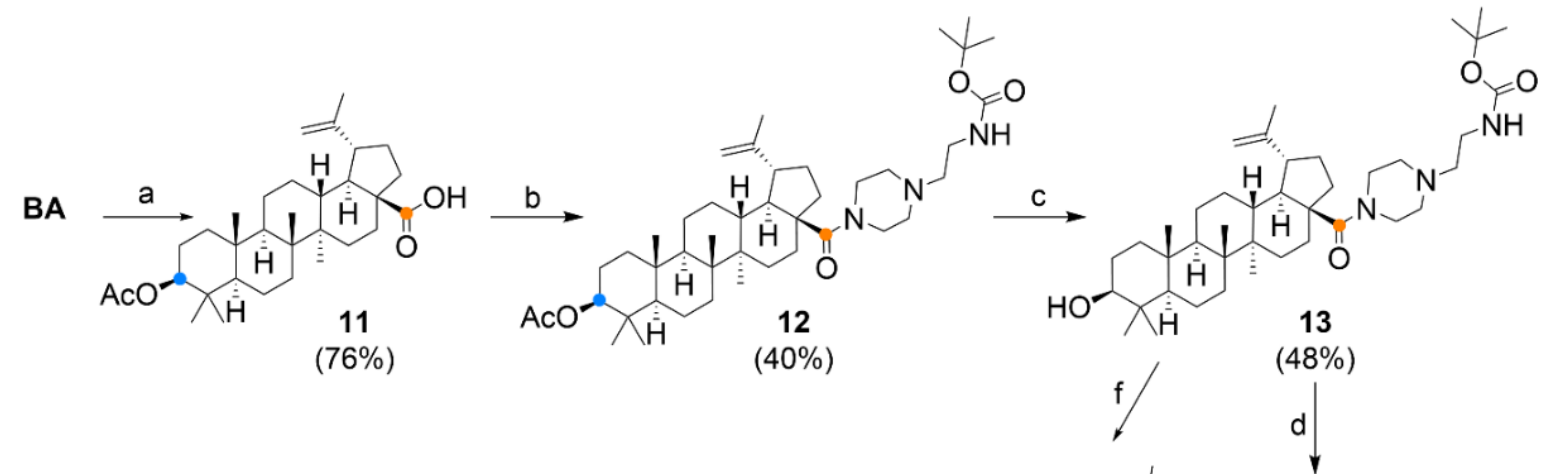

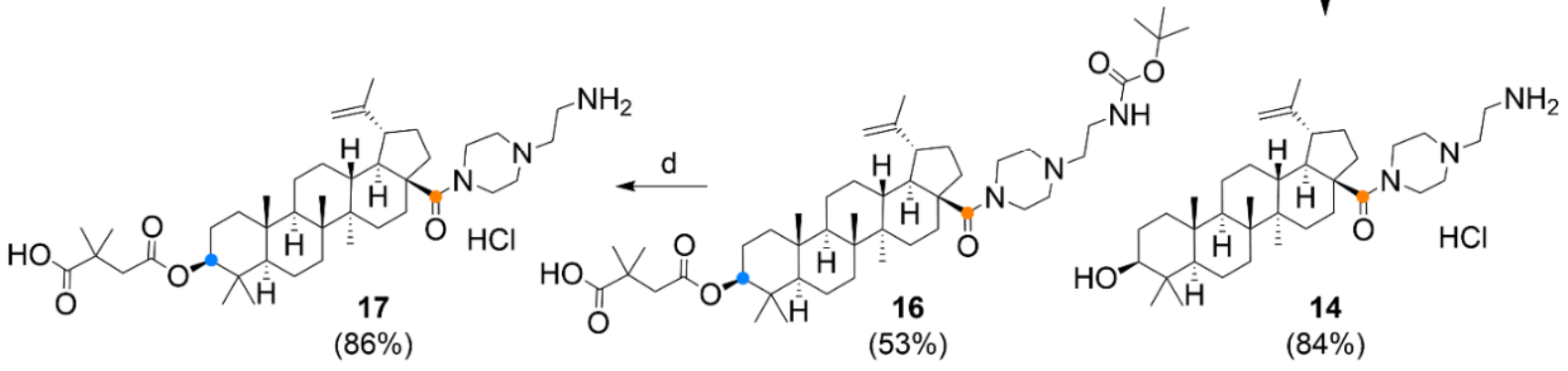

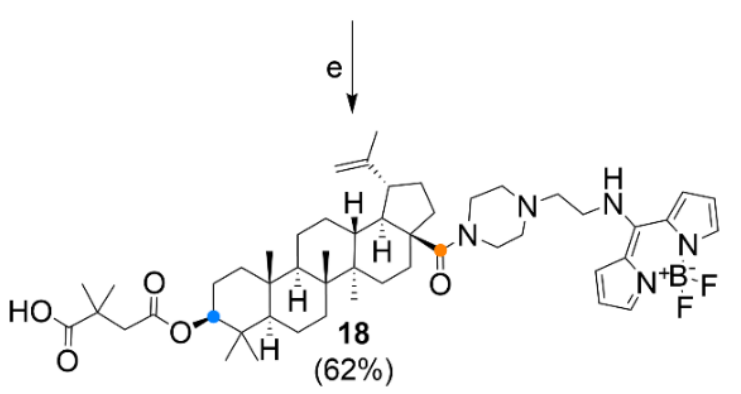

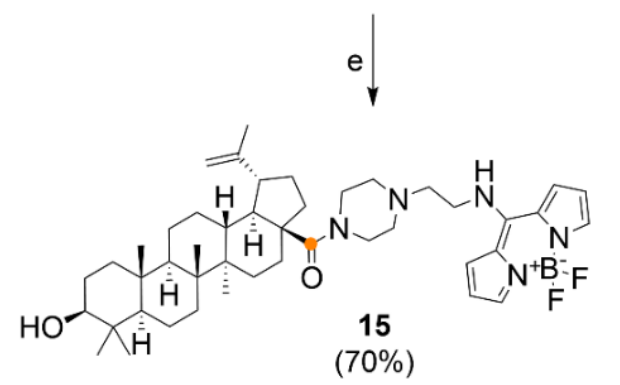

Figure 4. Synthesis of "piperazinyl" derivatives. Reagents and conditions: (a) $\mathrm{Ac}_{2} \mathrm{O}$, pyridine, $12 \mathrm{~h}, \mathrm{RT}$; (b) i. (COCl) 2 , DCM, DMF, 2 h, RT, ii. 1-(2-N-boc-aminoethyl)piperazine, Et ${ }_{3} \mathrm{~N}, \mathrm{DCM}, 12 \mathrm{~h}$, RT; (c) 4M NaOH, THF-MeOH, 3 h, RT; (d) 2M $\mathrm{HCl} / \mathrm{Et}_{2} \mathrm{O}, 12 \mathrm{~h}$, RT (under argon); (e) BODIPY-SMe, $\mathrm{CHCl}_{3}-\mathrm{THF}, \mathrm{Et}_{3} \mathrm{~N}, 30 \mathrm{~min}, \mathrm{RT}$; (f) 2,2-dimethyl succinic anhydride, 4-DMAP, $p$-TsOH, THF, $2 \mathrm{~h}, \mathrm{MW}-130^{\circ} \mathrm{C}$.

Experimental details of the preparation of substances are described in Section 2.1. and the NMR, HRMS spectra (Figures S1-S51) and photochemical properties (Figure S52 and Table S1) of the substances are shown in the Supplementary Material.

\subsection{Cytotoxicity on a Panel of Cell Lines}

The in vitro cytotoxicity of derivatives was assessed using MTS assay on the normal human foreskin and lung fibroblasts BJ and MRC-5 and cancer cell lines of a different histogenetic type (Table 1). Under the experimental conditions, BA and BT showed a weak or medium cytotoxic effect directed against cancer cell lines. Structures 5, 15 and 16 did not induce any cytotoxic effect in the entire cell line panel at the maximal tested concentration. Derivatives 4, 9, 12, 17 and 18 were inactive against the entire cell line panel except for the CCRF-CEM lymphoblastic leukaemia cell line. $\mathrm{IC}_{50}$ values obtained for these compounds in 
the sensitive cell line CCRF-CEM were between 5.76 and $23.65 \mu \mathrm{M}$. Derivatives 3, 6, 13 and 14 exerted high cytotoxicity against the entire cell line panel, including normal fibroblasts. The most potent compounds in the study were structures 3 and 14 with $\mathrm{IC}_{50}$ values 0.21 and $0.29 \mu \mathrm{M}$ in CCRF-CEM. Derivatives 2, 8 and 10 displayed medium cytotoxicity across the cell line panel. Derivatives $\mathbf{1}$ and $\mathbf{7}$ showed activity only against selected cell lines in the panel. Betulinic acid intermediate $\mathbf{1 1}$ was not tested. The MTS assay did not reveal any effect directed specifically against cancer cell lines, $\mathrm{IC}_{50}$ values calculated for normal fibroblast and cancer cell lines were highly comparable. Resistant sublines CEM-DNR and K562-Tax displayed for some compounds different sensitivity compared to their parental cell lines. As expected, a lower sensitivity was observed in the CEM-DNR resistant subline. The biggest difference in favour of CEM-DNR was observed for derivatives 6 and 3. BA and 13 showed an opposite profile in CEM-DNR and 1, 2, 3, 8 and 10 in the K562-Tax resistant subline, proposing better activity in resistant cell lines. Based on this data, we can speculate that there is a different mechanism in the elimination of cytotoxic derivatives. Several tested compounds are probably substrates of the P-glycoprotein as 4, 6, 13, 16, 17 and 18. However, not all data are in conclusion with P-glycoprotein transport, and we think that several tested derivatives could be substrates for LRP protein. Higher LRP expression in CEM-DNR and lower in K562-Tax correlates with cytotoxicity of the derivatives 1, 2, $3, \mathbf{8}, \mathbf{1 0}$. Derivative 13 is not active in the highly chemosensitive CCRF-CEM cell line, but comparable activity was observed in all tested cell lines, including non-tumour lines.

\subsection{Cell Cycle, Apoptosis and DNA/RNA Synthesis}

To reveal cytostatic effects, we examined proliferation markers and cell cycle profile of the sensitive CCRF-CEM cell line following a $24 \mathrm{~h}$ incubation with the derivatives (Table 2).

Exposure to $1 \times \mathrm{IC}_{50}$ and $5 \times \mathrm{IC}_{50}$ concentrations of derivatives did not induce DNA fragmentation with the exception of high doses of 2 and 8 . Treatment with $1 \times \mathrm{IC}_{50}$ concentrations did not modulate cell cycle profile while $5 \times \mathrm{IC}_{50}$ concentration led in all samples to a more pronounced effect. The treatment with $5 \times \mathrm{IC}_{50}$ derivatives $\mathbf{2 , 1 2}$ and 14 increased the percentage of cells in the S-phase by about 50\% compared to untreated control. Nevertheless, there was not any other prominent effect on the cell cycle profile or cell cycle arrest. To assess the impact of structures on CCRF-CEM proliferation potential, we monitored mitotic marker pH3Ser10 and proliferation marker BrDU after $24 \mathrm{~h}$ incubation with the compounds. Analysis of mitotic marker showed a low rate of cell division in cells treated with $5 \times \mathrm{IC}_{50}$ concentration of derivatives 2, 3, 6, 12 and 14. Derivatives 3, $6,8,10$, and 14 reduced the fraction of proliferating BrDU positive CCRF-CEM cells. In contrast, structures 2, 12 and 18 increased the percentage of cells incorporating BrDU into the DNA during pulse labelling. The complementary BrU based method of monitoring newly synthesized RNA in cells pre-incubated for 24 with the selected derivatives revealed stalled RNA synthesis induced by $5 \times \mathrm{IC}_{50}$ concentration of derivatives 2, 3, 8, 10, 14 and 17 . Compound 18 at a high concentration increased the percentage of BrU positive cells. Such an increase indicates the high transcription activity as a mark of replication stress leading to DNA damage and cell death [42]. Although there was observed a slight modulation of cell cycle profile induced by compound derivatives 2, 12 and 14, the overall cell cycle data indicates that there is no general cytostatic effect of tested betulinic acid derivatives. 
Table 1. Summary of cytotoxic activities $\left(\mathrm{IC}_{50}, \mu \mathrm{M}\right)$.

\begin{tabular}{|c|c|c|c|c|c|c|c|c|c|c|c|c|c|c|c|c|c|}
\hline $\begin{array}{l}\text { Compound } \\
\text { Cell Line }^{\text {a }}\end{array}$ & BA & BT & 1 & 2 & 3 & 4 & 6 & 7 & 8 & 9 & 10 & 12 & 13 & 14 & 16 & 17 & 18 \\
\hline CCRF-CEM & $>50$ & 12.82 & 8.98 & 8.14 & 0.21 & 23.65 & 1.55 & $>50$ & 8.18 & 22.48 & 2.92 & 9.62 & $>50$ & 0.29 & $>50$ & 5.76 & 8.61 \\
\hline CEM-DNR & 23.05 & 22.17 & 16.84 & 10.23 & 1.22 & $>50$ & 11.53 & $>50$ & 9.24 & $>50$ & 7.00 & $>50$ & 4.76 & 0.35 & $>50$ & $>50$ & $>50$ \\
\hline K562-Тax & $>50$ & 22.03 & 10.58 & 15.94 & 0.37 & $>50$ & 31.80 & $>50$ & 13.30 & $>50$ & 12.21 & $>50$ & 8.77 & 0.52 & $>50$ & $>50$ & $>50$ \\
\hline A549 & 22.68 & 23.06 & $>50$ & 22.87 & 1.80 & $>50$ & 6.65 & 21.29 & 18.84 & $>50$ & 13.55 & $>50$ & 5.15 & 1.26 & 44.93 & $>50$ & 47.80 \\
\hline HCT116 & $>50$ & 14.17 & $>50$ & 19.40 & 0.82 & $>50$ & 3.85 & $>50$ & 13.21 & $>50$ & 7.92 & $>50$ & 6.02 & 0.39 & 46.63 & $>50$ & 30.84 \\
\hline HCT116p53-I- & $>50$ & 18.20 & $>50$ & 29.24 & 0.44 & $>50$ & 3.39 & $>50$ & 21.56 & $>50$ & 8.80 & $>50$ & 4.99 & 0.44 & 44.76 & $>50$ & 45.50 \\
\hline MRC-5 & $>50$ & $>50$ & $>50$ & 24.19 & 2.59 & $>50$ & 8.07 & 17.58 & 23.14 & $>50$ & 14.12 & $>50$ & 5.18 & 1.58 & 44.61 & $>50$ & $>50$ \\
\hline BJ & $>50$ & $>50$ & $>50$ & 25.33 & 1.91 & $>50$ & 8.37 & 20.69 & 21.54 & $>50$ & 15.49 & $>50$ & 5.36 & 1.59 & 47.63 & $>50$ & $>50$ \\
\hline
\end{tabular}

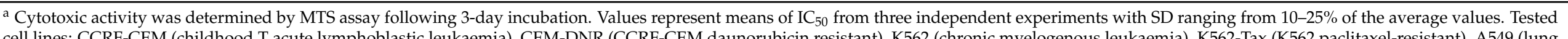

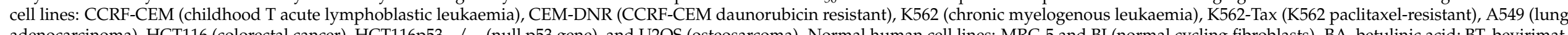

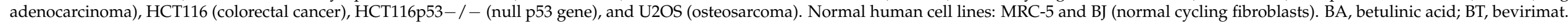


Table 2. Effect of cytotoxic compounds on cell cycle, apoptosis and DNA/RNA synthesis in CCRF-CEM lymphoblasts (\% of positive cells).

\begin{tabular}{|c|c|c|c|c|c|c|c|}
\hline Compound & $<\mathrm{G} 1$ & G0/G1 & S & $\mathrm{G} 2 / \mathrm{M}$ & $\mathrm{pH} 3^{\operatorname{Ser} 10 a}$ & $\mathrm{BrDU}^{b}$ & $\mathrm{BrU}^{c}$ \\
\hline control & 2.20 & 40.77 & 37.64 & 21.60 & 1.77 & 37.22 & 40.77 \\
\hline $1 \bigcirc$ & 1.36 & 37.03 & 44.13 & 18.84 & 1.53 & 36.54 & 52.69 \\
\hline 10 & 1.93 & 42.33 & 35.87 & 21.80 & 1.71 & 37.99 & 44.47 \\
\hline 20 & 4.33 & 39.88 & 46.65 & 13.47 & 1.33 & 52.07 & 28.60 \\
\hline 20 & 41.17 & 23.94 & 56.21 & 19.85 & 0.58 & 22.75 & 4.05 \\
\hline 30 & 1.30 & 35.07 & 36.54 & 28.40 & 2.04 & 41.88 & 50.56 \\
\hline 30 & 3.53 & 31.73 & 41.18 & 27.09 & 0.16 & 2.06 & 0.40 \\
\hline 60 & 2.23 & 33.39 & 49.74 & 16.87 & 1.50 & 44.97 & 42.25 \\
\hline 60 & 5.24 & 37.16 & 39.52 & 23.32 & 0.50 & 7.10 & 26.05 \\
\hline 80 & 2.64 & 31.93 & 47.72 & 20.35 & 1.70 & 46.44 & 33.61 \\
\hline 80 & 39.65 & 40.78 & 37.66 & 21.56 & 1.25 & 8.51 & 1.85 \\
\hline 10 & 3.80 & 37.98 & 44.59 & 17.43 & 1.44 & 42.25 & 35.04 \\
\hline 10 & 10.69 & 44.58 & 42.32 & 13.10 & 1.25 & 10.18 & 13.02 \\
\hline 120 & 2.45 & 33.64 & 43.16 & 23.20 & 1.40 & 59.73 & 41.98 \\
\hline 12 & 3.01 & 29.75 & 56.69 & 13.55 & 0.68 & 64.07 & 34.00 \\
\hline $14 \bigcirc$ & 8.63 & 21.46 & 56.29 & 22.25 & 0.15 & 24.55 & 1.56 \\
\hline 140 & 8.16 & 27.28 & 51.82 & 20.90 & 0.18 & 0.52 & 1.53 \\
\hline $17 \bigcirc$ & 2.89 & 34.83 & 46.96 & 18.21 & 1.56 & 48.07 & 26.70 \\
\hline 170 & 4.04 & 43.42 & 38.47 & 18.10 & 1.49 & 29.41 & 3.39 \\
\hline 18 & 2.06 & 36.06 & 44.31 & 19.63 & 1.25 & 55.81 & 46.98 \\
\hline 180 & 2.97 & 38.01 & 44.12 & 17.87 & 1.55 & 49.64 & 70.23 \\
\hline
\end{tabular}

Flow cytometry analysis was used for quantification of cell cycle distribution and apoptotic cells with a concentration of compounds equal to $1 \times \mathrm{IC}_{50}(\bullet)$ and $5 \times \mathrm{IC}_{50}(\bullet)$ values. ${ }^{a}$ phospho-Histone (Ser10); ${ }^{b}$ 5-bromo-2-deoxyuridine; ${ }^{c} \mathrm{BrU}$, 5 -bromouridine.

\subsection{Live Cells Imaging}

The group of six derivatives of BA and BODIPY was studied on the U2OS-Nuc cell line with the nucleus labelled by fluorescein protein mCherry. The functionalized BODIPY dyes (BODIPY-CO ${ }_{2} \mathbf{H}$ and BODIPY-NH $\mathbf{N}_{2}$ ), as well as precursor BODIPY-SMe, were used as a control. All fluorescent microscopic images of this pilot experiment are shown in Figure S53. To achieve a better specificity of the staining, we have focused on the short incubation with the fluorescent conjugates. After short incubation $(1 \mathrm{~h})$, conjugates 4 and $\mathbf{6}$ out of this group of derivatives were localized in living cells, but only with the weak signal in the nucleus of the studied cell line (Figure 5B-Pearson's and Mander's coefficients). The functionalized BODIPY dyes were not detected in the U2OS-Nuc cell line and thus it is highly possible that cellular uptake of conjugates $\mathbf{4}$ and $\mathbf{6}$ is due to their groups on BA residue. Other studied derivatives of BA and BODIPY were not detected in living cells under our experimental conditions; however, it is possible that the signal can be observed at later intervals. BODIPY-SMe is reactive due to the 8-thiomethyl group and it was predicted to penetrate cell compartments; this was confirmed by fluorescent microscopy.

To further study the cellular localization of conjugates $\mathbf{4}$ and $\mathbf{6}$, we decided to continue with fluorescent microscopy on cell lines with fluorescently labelled structures of mitochondria, endoplasmic reticulum, and Golgi apparatus, which are the most published targets of BA $[29,30]$. The results of these colocalization experiments are shown in Figure 5. Both conjugates demonstrated presence in multiple cellular structures. Pearson's coefficient (Figure 5B) showed the highest correlation of signal in U2OS-ER cell line, and then in U2OS-Mito cell line and the lowest correlation was measured in U2OS-GA cell line. When we expressed colocalization by Mander's coefficient (overlap of red channel compared to the blue channel), which is more specific for colocalization calculation of signal presented in multiple cellular structures, the obtained data showed both conjugates $\mathbf{4}$ and $\mathbf{6}$ almost perfectly label mitochondria and endoplasmic reticulum. The lowest colocalization signal was again detected in the U2OS-GA cell line. BODIPY-SMe was used based on the data 
from the pilot experiment as a positive control with perfect colocalization in all studied cell lines. Images with entire microscopic fields are shown in Figures S54-S56.

A
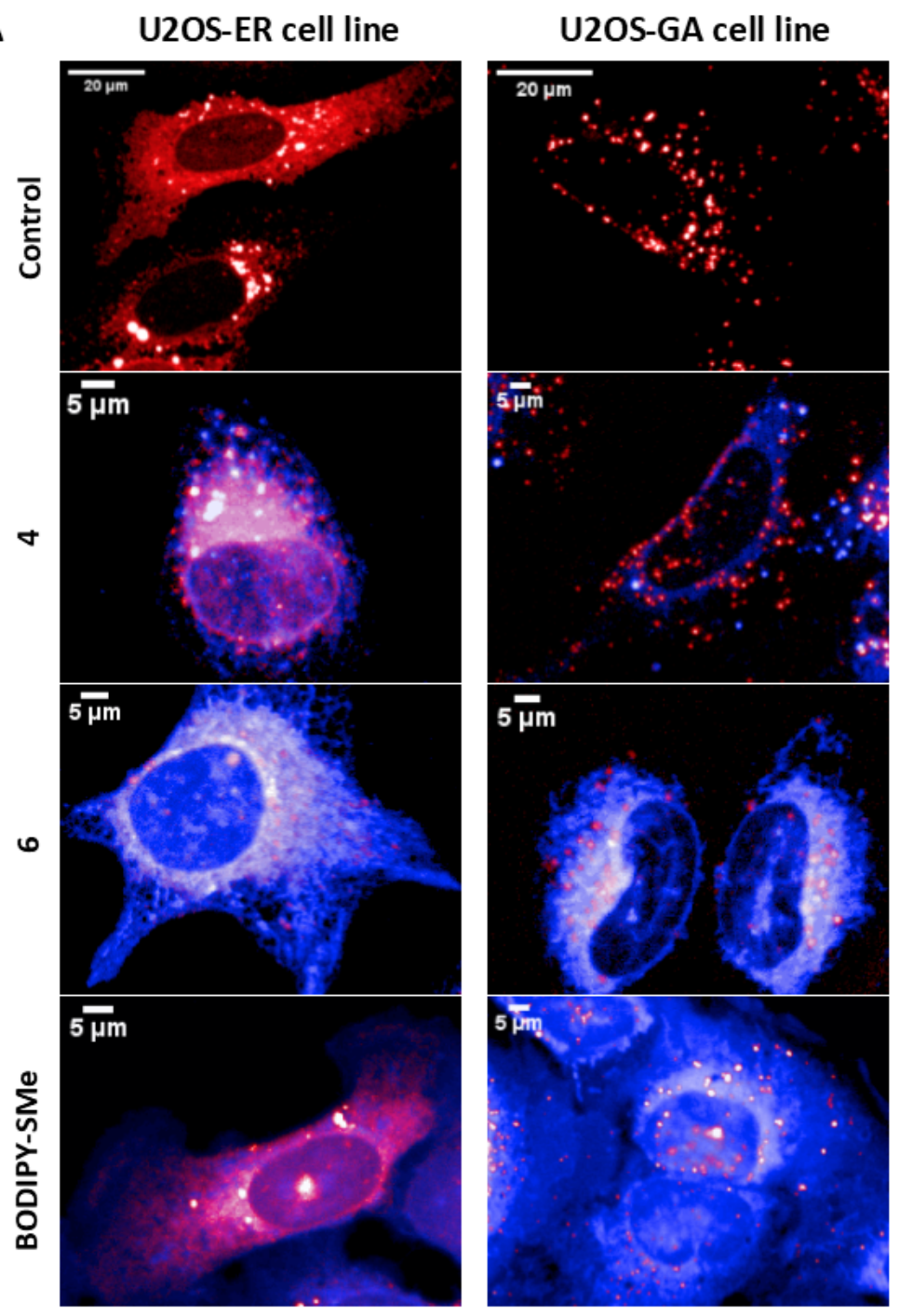

U2OS-Mito cell line
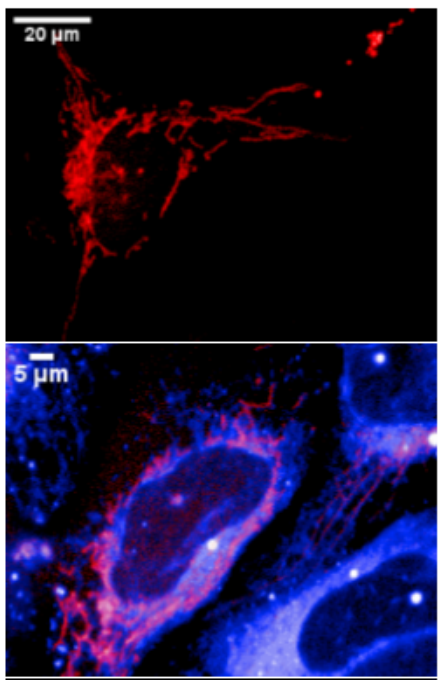

$\overline{5} \overline{\mathrm{mm}}$
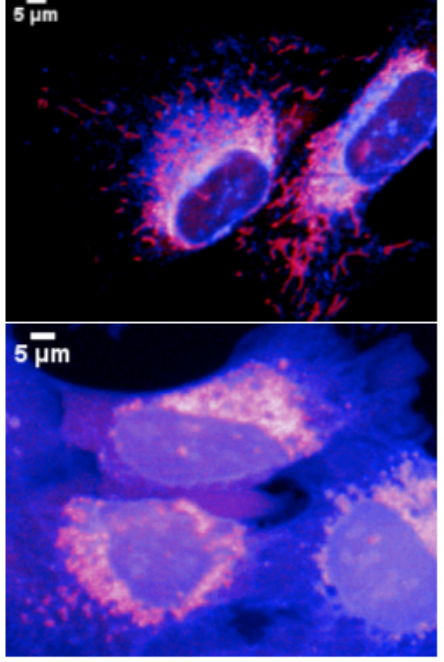

B

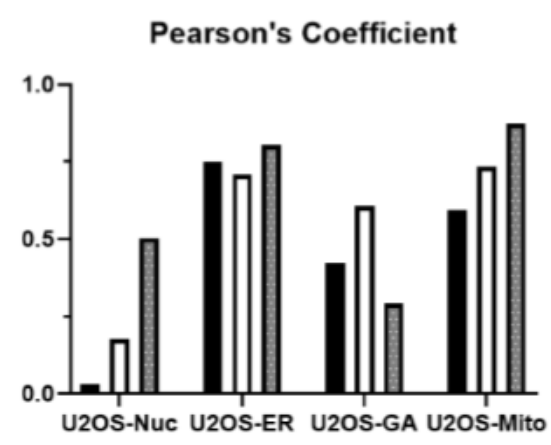

Figure 5. Live cell imaging and colocalization experiments of active compounds $(4,6)$ and BODIPY-SMe (panel A) and visualization of Pearson's and Mander's coefficient (panel B).

To conclude our results from fluorescent microscopy study of six derivatives of BA and BODIPY, only conjugates $\mathbf{4}$ and $\mathbf{6}$ are detected in living cells under our experimental conditions ( $1 \mathrm{~h}$ following the treatment). Furthermore, we were able to almost perfectly 
colocalize both conjugates with cellular structures as endoplasmic reticulum and mitochondria, which is in agreement with data published in the past [21]. Compound 4 has, in its structure, fluorophore attached to the carboxyl group at the C-28 position, thus it is more similar to the pristine structure of BA and has low cytotoxicity (close to free BA). Conversely, compound 6 contains a conjugated amine at the C-28 position and the fluorophore is attached to the hydroxyl group at the C-3 position of BA. Its cytotoxicity is markedly more pronounced than in the case of substance 4. It is clear that the "polar head" of the molecule is responsible for cytotoxicity. Moreover, this moiety can be used for the intracellular targeted delivery, or organelle/mitochondrion targeting, as is described by the previous research works $[43,44]$. As the localization of both compounds is similar, it is likely that the direct target remained unchanged, but the effect of compound $\mathbf{6}$ was potentiated by the presence of free amine moiety in the molecule. The localization of the compounds in lipid rich compartments (mitochondria, endoplasmic reticulum) can also be explained by the lipid character of the BA and its analogues. The calculated values of lipophilicity $(\log \mathrm{P})$ of the substances are close to BA (Table S2). The acidity constants (pKa) are indicative and their reproducibility is difficult because, in comparison with BA, the compounds described here are mostly in the form of amide or ester derivatives.

\subsection{Anti-HIV Activity}

Bevirimat (3-O- $\left(3^{\prime}, 3^{\prime}\right.$-dimethylsuccinyl) betulinic acid) and its derivatives were shown to be maturation inhibitors of HIV-1 [45-47]. By binding to the CA-SP1 region of HIV1 Gag polyprotein, bevirimat prevents HIV-1 protease-mediated release of C-terminal part of CA from a spacer peptide 1 (SP1) [48]. This results in a block of the final step of virus maturation and subsequently abolishes HIV-1 infectivity. An atomic model of HIV-1 CA-SP1 suggested that this inhibitor stabilizes the CA-SP1 structure, thus preventing the proteolytic cleavage [49]. Although bevirimat is a potent inhibitor of HIV-1 maturation, its clinical development was discontinued in 2010 due to the bevirimat resistance caused by Gag SP1 natural polymorphism (Q6, V7 and T8) [50-52]. However, bevirimat derivatives with modification at the C-28 position seem to overcome the problem with HIV-1 resistance $[53,54]$. Here, using VSV-G pseudotyped HIV-1 particles, we tested the effect of 17 BA derivatives on HIV-1 maturation and infectivity. The $50 \%$ cytotoxic concentration $\left(\mathrm{IC}_{50}\right)$ of the compounds was first evaluated by Resazurin assay. Two of the tested compounds, 3 and 14, were highly toxic to HEK 293 cells at a concentration lower than $5 \mu \mathrm{M}$ and significant cytotoxicity was also found for compound $6\left(\mathrm{IC}_{50} 12 \mu \mathrm{M}\right)$ (Table 3 ).

Table 3. Cytotoxicity and anti-HIV-1 activity of the tested compounds ${ }^{\mathrm{a}}$.

\begin{tabular}{|c|c|c|c|c|c|c|c|c|c|c|c|c|c|c|c|}
\hline Compd. & 1 & 2 & 4 & 5 & 6 & 7 & 8 & 9 & 10 & 12 & 13 & 15 & 16 & 17 & 18 \\
\hline $\mathrm{IC}_{50}[\mu \mathrm{M}]$ & $>40$ & 36.4 & $>40$ & $>40$ & 12.0 & $>40$ & 37.8 & $>40$ & $>40$ & $>40$ & $>40$ & $>40$ & $>40$ & $>40$ & $>40$ \\
\hline $\mathrm{IC}_{50 \mathrm{i}}[\mu \mathrm{M}]$ & $>50$ & 11.7 & 44.1 & $>50$ & n.d. & $>50$ & 1.4 & 14.0 & 8.4 & 31.9 & $>50$ & $>50$ & 9.1 & 7.6 & 7.1 \\
\hline
\end{tabular}

${ }^{a}$ HEK 293 cells were grown in the presence or absence of tested compounds at a concentration ranging from 5 to $40 \mu \mathrm{M}$. The viability of the cells was determined by Resazurin assay $48 \mathrm{~h}$ later ( $($ ). To determine the effect of the compounds on HIV-1 infectivity ( $)$, HEK 293 cells were transfected with the lentiviral vectors and treated with the tested compounds. The cells producing HIV-1 particles in the presence or absence of DMSO (at a final concentration of 1\%) were used as controls. At $48 \mathrm{~h}$ post-transfection, the content of HIV-1 capsid (CA) protein from the culture media was quantified by ELISA and normalized amounts of VSV-G pseudotyped HIV-1 viruses were used to infect fresh HEK 293 cells. HIV-1 infectivity was determined $48 \mathrm{~h}$ later by quantification of GFP-producing cells by flow cytometry. The $50 \%$ infection inhibition $\left(\mathrm{IC}_{50 \mathrm{i}}\right)$ was defined as the concentration of the compound that reduced the HIV-1 infectivity by $50 \%$ compared to the untreated controls.

Apart from these three cytotoxic compounds, 14 fewer toxic compounds were used in the HIV-1 single-round infectivity assay. HIV-1 particles pseudotyped with VSV glycoproteins were produced in HEK 293 cells in the presence of tested compounds. At $48 \mathrm{~h}$ post-transfection, the content of HIV-1 capsid (CA) protein from the culture media was quantified by ELISA and normalized amounts of VSV-G pseudotyped HIV-1 viruses were used to infect fresh HEK 293 cells. At $48 \mathrm{~h}$ post-infection, the HIV-1 infectivity was determined by quantification of GFP-producing cells by flow cytometry. The $50 \%$ infection 
inhibition $\left(\mathrm{IC}_{50 \mathrm{i}}\right)$ was defined as the concentration of the compound that reduced the HIV-1 infectivity by $50 \%$ compared to the untreated controls (Table 3). The compounds 1, 7, 13, 15 and 5 did not exhibit any potent anti-HIV-1 activity (data not shown). Conversely, compounds 2, 4, 9 and 12 inhibited anti-HIV-1 activity with $\mathrm{IC}_{50 \mathrm{i}}$ from 11.7 to $44.1 \mu \mathrm{M}$. The compounds $\mathbf{8}, \mathbf{1 0}, \mathbf{1 6}, \mathbf{1 7}$ and $\mathbf{1 8}$ inhibited HIV-1 with $\mathrm{IC}_{50 \mathrm{i}}$ below $10 \mu \mathrm{M}$ (Table 3). To analyse whether these bevirimat derivatives also act as maturation inhibitors of CA-SP1 cleavage, the HIV-1 virions released from the HEK 293 cells treated with the selected compounds $(2,4,8,9,10,12,16,17$ and 18) were analysed by Western blot using anti-HIV-1 CA antibody (Figure 6).

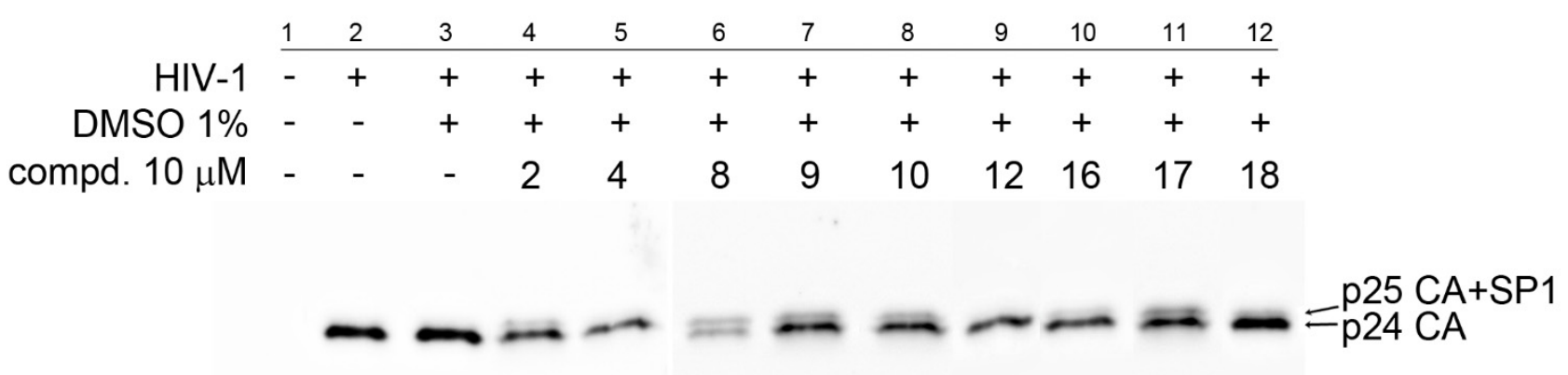

Figure 6. Effect of selected tested compounds on CA-SP1 processing of HIV-1 Gag polyprotein. HEK 293 cells produced HIV-1 particles pseudotyped with VSV-glycoproteins in the absence (lanes 2 and 3) or presence of selected tested compounds (lanes 4-12). At $48 \mathrm{~h}$ post-transfection, VSV-G pseudotyped HIV-1 viruses released from the HEK 293 cells were analysed by Western blot using an anti-HIV-1 CA antibody (duplicate of blot shown in Figure S57).

Only completely processed p24 CA of molecular weight of $24 \mathrm{kDa}$ was identified in the viruses formed in the presence of compounds 4 and 12. However, in the samples treated with compounds $2,8,9,10,16,17$ and 18 , we identified not only fully processed p24 CA, but also p25 CA-SP1 protein. This observation suggests a similar mechanism of inhibition as described for bevirimat, i.e., the block of the final step of HIV-1 maturation.

\section{Conclusions}

This study describes the synthesis and biological evaluation of 17 betulinic acid derivatives. The biological profiling revealed that BA derivatives 3 and $\mathbf{1 4}$ with modification at $\mathrm{C}-28$ show increased cytotoxicity. However, the cytotoxicity was not specifically directed against cancer cell lines and was not associated with cell cycle arrest. The most effective compounds with sub-micromolar $\mathrm{IC}_{50}$ values $\mathbf{3}$ and $\mathbf{1 4}$ possess a hydroxyl group at C-3, whereas structures with a succinyl hemiester group displayed medium cytotoxicity or were inactive. The study introduced six original structures with BODIPY moiety linked to the lupane skeleton. BODIPY conjugates 4, 5, 15 and 18 showed low or no cytotoxic activity. In contrast, BODIPY derivative 6 induced strong and derivative 10 medium cytotoxicity in the entire cell line panel, although they do not share any similar substituents at positions C-3 and C-28. The cellular localization of BODIPY conjugates was further studied in U2OS cells using fluorescent microscopy. Fluorescent derivatives $\mathbf{4}$ and $\mathbf{6}$ colocalized with endoplasmic reticulum and mitochondria, which is in agreement with previous studies showing interaction with the processes and proteins localized in these organelles $[55,56]$. Uncoupling of the mitochondrial respiration, followed by radical burst and mitochondrial membrane disruption, is one of the well-described effects of betulin and betulinic acid [57-60]. Thus, we believe that reliable tools to study the derivatives of BA on living cells were established. The anti-HIV-1 activity showed that compounds 2, 8, 9, 10, 16 and 18 with $\mathrm{IC}_{50 \mathrm{i}}$ lower than $10 \mu \mathrm{M}$ did not fully process the p24 CA and p25 CA-SP1 proteins, suggesting a similar mechanism of inhibition as described for bevirimat. 
Supplementary Materials: The following are available online at https:/ / www.mdpi.com/article/10 .3390 / biomedicines9091104/s1. Supplementary Figures S1-S52 and Table S1 document the analytical identification (NMR, HRMS, UV-Vis and fluorescence). Table S2: Calculated physical properties (pKa and $\log \mathrm{P}$ ) of the derivatives. Figures S53-S56 show supplementary pictures from fluorescent microscopy. Figure S57: Effect of selected tested compounds on CA-SP1 processing of HIV-1 Gag polyprotein (a duplicate of western blot showed in Figure 5. in the article).

Author Contributions: M.J., P.D., P.B.D., M.R. and M.H. conceived and designed the experiments; D.K., T.Z., M.J., P.D., I.K., J.S., S.G., J.Ǩ. and P.D. performed the experiments; M.J., P.D. and M.R. analysed the data; M.J., P.D. and M.R. prepared the manuscript; P.B.D. and M.H. edited the article. All authors have read and agreed to the published version of the manuscript.

Funding: This work was supported by GA CR (CZ) GA20-19906S, by the Czech Ministry of Education, Youth and Sports (CZ-OPENSCREEN-LM2018130, and EATRIS-CZ-LM2018133, Czech-BioImagingLM2018129) and internal grant of Palacky University (IGA_LF_2021_038).

Conflicts of Interest: The authors declare that they have no known competing financial interests or personal relationships that could have appeared to influence the work reported in this paper.

\section{References}

1. Sousa, J.L.C.; Freire, C.S.R.; Silvestre, A.J.D.; Silva, A.M.S. Recent developments in the functionalization of betulinic acid and its natural analogues: A route to new bioactive compounds. Molecules 2019, 24, 355. [CrossRef]

2. Zuco, V.; Supino, R.; Righetti, S.C.; Cleris, L.; Marchesi, E.; Gambacorti-Passerini, C.; Formelli, F. Selective cytotoxicity of betulinic acid on tumor cell lines, but not on normal cells. Cancer Lett. 2002, 175, 17-25. [CrossRef]

3. Pisha, E.; Chai, H.; Lee, I.S.; Chagwedera, T.E.; Farnsworth, N.R.; Cordell, G.A.; Beecher, C.W.W.; Fong, H.H.S.; Kinghorn, A.D.; Brown, D.M.; et al. Discovery of betulinic acid as a selective inhibitor of human melanoma that functions by induction of apoptosis. Nat. Med. 1995, 1, 1046-1051. [CrossRef] [PubMed]

4. Noda, Y.; Kaiya, T.; Kohda, K.; Kawazoe, Y. Enhanced cytotoxicity of some triterpenes toward leukemia L1210 cells cultured in low pH media: Possibility of a New Mode of Cell Killing. Chem. Pharm. Bull. 1997, 45, 1665-1670. [CrossRef] [PubMed]

5. Fujioka, T.; Kashiwada, Y.; Kilkuskie, R.E.; Cosentino, L.M.; Ballas, L.M.; Jiang, J.B.; Janzen, W.P.; Chen, I.-S.; Lee, K.-H. Anti-AIDS agents, 11. Betulinic acid and platanic acid as anti-HIV principles from Syzigium claviflorum, and the anti-HIV activity of structurally related triterpenoids. J. Nat. Prod. 1994, 57, 243-247. [CrossRef]

6. Kodr, D.; Rumlová, M.; Zimmermann, T.; Džubák, P.; Drašar, P.; Jurášek, M. Antitumor and anti-HIV derivatives of betulinic acid. Chem. Listy 2020, 114, 658-667.

7. Fulda, S.; Friesen, C.; Los, M.; Scaffidi, C.; Mier, W.; Benedict, M.; Nunez, G.; Krammer, P.H.; Peter, M.E.; Debatin, K.M. Betulinic acid triggers CD95 (APO-1/Fas)- and p53-independent apoptosis via activation of caspases in neuroectodermal tumors. Cancer Res. 1997, 57, 4956-4964. [PubMed]

8. Fulda, S.; Scaffidi, C.; Susin, S.A.; Krammer, P.H.; Kroemer, G.; Peter, M.E.; Debatin, K.M. Activation of mitochondria and release of mitochondrial apoptogenic factors by betulinic acid. J. Biol. Chem. 1998, 273, 33942-33948. [CrossRef]

9. Liu, W.K.; Ho, J.C.K.; Cheung, F.W.K.; Liu, B.P.L.; Ye, W.C.; Che, C.T. Apoptotic activity of betulinic acid derivatives on murine melanoma B16 cell line. Eur. J. Pharmacol. 2004, 498, 71-78. [CrossRef]

10. Fulda, S.; Jeremias, I.; Steiner, H.H.; Pietsch, T.; Debatin, K.M. Betulinic acid: A new cytotoxic agent against malignant brain-tumor cells. Int. J. Cancer 1999, 82, 435-441. [CrossRef]

11. Mullauer, F.B.; van Bloois, L.; Daalhuisen, J.B.; Ten Brink, M.S.; Storm, G.; Medema, J.P.; Schiffelers, R.M.; Kessler, J.H. Betulinic acid delivered in liposomes reduces growth of human lung and colon cancers in mice without causing systemic toxicity. Anti-Cancer Drug 2011, 22, 223-233. [CrossRef]

12. Takada, Y.; Aggarwal, B.B. Betulinic acid suppresses carcinogen-induced NF-kappa B activation through inhibition of I kappa B alpha kinase and 665 phosphorylation: Abrogation of cyclooxygenase-2 and matrix metalloprotease-9. J. Immunol. 2003, 171, 3278-3286. [CrossRef]

13. Melzig, M.F.; Bormann, H. Betulinic acid inhibits aminopeptidase N activity. Planta Med. 1998, 64, 655-657. [CrossRef]

14. Kwon, H.J.; Shim, J.S.; Kim, J.H.; Cho, H.Y.; Yum, Y.N.; Kim, S.H.; Yu, J. Betulinic acid inhibits growth factor-induced in vitro angiogenesis via the modulation of mitochondrial function in endothelial cells. Jpn. J. Cancer Res. 2002, 93, 417-425. [CrossRef]

15. Kashiwada, Y.; Nagao, T.; Hashimoto, A.; Ikeshiro, Y.; Okabe, H.; Cosentino, L.M.; Lee, K.-H. Anti-AIDS agents 38. Anti-HIV activity of 3-O-acyl ursolic acid derivatives. J. Nat. Prod. 2000, 63, 1619-1622. [CrossRef] [PubMed]

16. Sundquist, W.I.; Krausslich, H.G. HIV-1 Assembly, budding, and maturation. Cold Spring Harb. Perspect. Med. 2012 , 2, a006924. [CrossRef] [PubMed]

17. Smith, P.F.; Ogundele, A.; Forrest, A.; Wilton, J.; Salzwedel, K.; Doto, J.; Allaway, G.P.; Martin, D.E. Phase I and II study of the safety, virologic effect, and pharmacokinetics/pharmacodynamics of single-dose 3-O- $\left(3^{\prime}, 3^{\prime}\right.$-dimethylsuccinyl)betulinic acid (bevirimat) against human immunodeficiency virus infection. Antimicrob. Agents Chemother. 2007, 51, 3574-3581. [CrossRef] [PubMed] 
18. Martin, D.E.; Blum, R.; Wilton, J.; Doto, J.; Galbraith, H.; Burgess, G.L.; Smith, P.C.; Ballow, C. Safety and pharmacokinetics of bevirimat (PA-457), a novel inhibitor of human immunodeficiency virus maturation, in healthy volunteers. Antimicrob. Agents Chemother. 2007, 51, 3063. [CrossRef]

19. Martin, D.E.; Blum, R.; Doto, J.; Galbraith, H.; Ballow, C. Multiple-Dose Pharmacokinetics and safety of bevirimat, a novel inhibitor of HIV maturation, in healthy volunteers. Clin. Pharmacokinet. 2007, 46, 589-598. [CrossRef] [PubMed]

20. Margot, N.A.; Gibbs, C.S.; Miller, M.D. Phenotypic susceptibility to bevirimat in isolates from HIV-1-infected patients without prior exposure to bevirimat. Antimicrob. Agents Chemother. 2010, 54, 2345-2353. [CrossRef] [PubMed]

21. Zhao, Y.; Gu, Q.; Morris-Natschke, S.L.; Chen, C.-H.; Lee, K.-H. Incorporation of privileged structures into bevirimat can improve activity against wild-type and bevirimat-resistant HIV-1. J. Med. Chem. 2016, 59, 9262-9268. [CrossRef]

22. Zhao, Y.; Chen, C.-H.; Morris-Natschke, S.L.; Lee, K.-H. Design, synthesis, and structure activity relationship analysis of new betulinic acid derivatives as potent HIV inhibitors. Eur. J. Med. Chem. 2021, 215, 113287. [CrossRef]

23. Mukherjee, R.; Jaggi, M.; Rajendran, P.; Siddiqui, M.J.A.; Srivastava, S.K.; Vardhan, A.; Burman, A.C. Betulinic acid and its derivatives as anti-angiogenic agents. Bioorg. Med. Chem. Lett. 2004, 14, 2181-2184. [CrossRef]

24. Kim, J.Y.; Koo, H.M.; Kim, D.S.H.L. Development of C-20 modified betulinic acid derivatives as antitumor agents. Bioorg. Med. Chem. Lett. 2001, 11, 2405-2408. [CrossRef]

25. Chowdhury, A.R.; Mandal, S.; Mittra, B.; Sharma, S.; Mukhopadhyay, S.; Majumder, H.K. Betulinic acid, a potent inhibitor of eukaryotic topoisomerase I: Identification of the inhibitory step, the major functional group responsible and development of more potent derivatives. Med. Sci. Monit. 2002, 8, BR254-BR265. [PubMed]

26. Bildziukevich, U.; Rarova, L.; Janovska, L.; Saman, D.; Wimmer, Z. Enhancing effect of cystamine in its amides with betulinic acid as antimicrobial and antitumor agent in vitro. Steroids 2019, 148, 91-98. [CrossRef] [PubMed]

27. Bildziukevich, U.; Vida, N.; Rárová, L.; Kolář, M.; Šaman, D.; Havlíček, L.; Drašar, P.; Wimmer, Z. Polyamine derivatives of betulinic acid and beta-sitosterol: A comparative investigation. Steroids 2015, 100, 27-35. [CrossRef] [PubMed]

28. Brandes, B.; Hoenke, S.; Fischer, L.; Csuk, R. Design, synthesis and cytotoxicity of BODIPY-FL labelled triterpenoids. Eur. J. Med. Chem. 2020, 185, 111858. [CrossRef] [PubMed]

29. Krajčovičová, S.; Staňková, J.; Džubák, P.; Hajdúch, M.; Soural, M.; Urban, M. A synthetic approach for the rapid preparation of BODIPY conjugates and their use in imaging of cellular drug uptake and distribution. Chem. Eur. J. 2018, 24, 4957-4966. [CrossRef] [PubMed]

30. Sommerwerk, S.; Heller, L.; Kerzig, C.; Kramell, A.E.; Csuk, R. Rhodamine B conjugates of triterpenoic acids are cytotoxic mitocans even at nanomolar concentrations. Eur. J. Med. Chem. 2017, 127, 1-9. [CrossRef]

31. Pal, A.; Ganguly, A.; Chowdhuri, S.; Yousuf, M.; Ghosh, A.; Barui, A.K.; Kotcherlakota, R.; Adhikari, S.; Banerjee, R. Bis-arylidene oxindole-betulinic acid conjugate: A fluorescent cancer cell detector with potent anticancer activity. ACS Med. Chem. Lett. 2015, 6, 612-616. [CrossRef] [PubMed]

32. Rumlová, M.; Kř́žžová, I.; Keprová, A.; Hadravová, R.; Doležal, M.; Strohalmová, K.; Pichová, I.; Hájek, M.; Ruml, T. HIV-1 protease-induced apoptosis. Retrovirology 2014, 11, 37. [CrossRef]

33. Dostálková, A.; Kaufman, F.; Křížová, I.; Kultová, A.; Strohalmová, K.; Hadravová, R.; Ruml, T.; Rumlová, M. Mutations in the basic region of the Mason-Pfizer monkey virus nucleocapsid protein affect reverse transcription, genomic RNA packaging, and the virus assembly site. J. Virol. 2018, 92, e00106-18. [CrossRef]

34. Křǐžová, I.; Hadravová, R.; Štokrová, J.; Günterová, J.; Doležal, M.; Ruml, T.; Rumlová, M.; Pichová, I. The G-patch domain of Mason-Pfizer monkey virus is a part of reverse transcriptase. J. Virol. 2012, 86, 1988. [CrossRef] [PubMed]

35. Strohalmová-Bohmová, K.; Spiwok, V.; Lepšík, M.; Hadravová, R.; Kř́ižová, I.; Ulbrich, P.; Pichová, I.; Bednárová, L.; Ruml, T.; Rumlová, M. Role of Mason-Pfizer monkey virus CA-NC spacer peptide-like domain in assembly of immature particles. J. Virol. 2014, 88, 14148. [CrossRef]

36. Goud, T.V.; Tutar, A.; Biellmann, J.-F. Synthesis of 8-heteroatom-substituted 4,4-difluoro-4-bora-3a,4a-diaza-s-indacene dyes (BODIPY). Tetrahedron 2006, 62, 5084-5091. [CrossRef]

37. Kim, D.; Ma, D.; Kim, M.; Jung, Y.; Kim, N.H.; Lee, C.; Cho, S.W.; Park, S.; Huh, Y.; Jung, J.; et al. Fluorescent labeling of protein using blue-emitting 8-amino-BODIPY derivatives. J. Fluoresc. 2017, 27, 2231-2238. [CrossRef]

38. Chang, Y.-T.; Alamudi, S.H.; Satapathy, R.; Su, D. Background-free fluorescent probes for live cell imaging. US Patent WO2017078623A1, 2017.

39. Qian, K.; Bori, I.D.; Chen, C.-H.; Huang, L.; Lee, K.-H. Anti-AIDS agents 90. Novel C-28 modified bevirimat analogues as potent HIV maturation inhibitors. J. Med. Chem. 2012, 55, 8128-8136. [CrossRef] [PubMed]

40. Staudinger, H.; Meyer, J. Über neue organische Phosphorverbindungen III. Phosphinmethylenderivate und Phosphinimine. Helv. Chim. Acta 1919, 2, 635-646. [CrossRef]

41. Neises, B.; Steglich, W. Simple method for the esterification of carboxylic acids. Angew. Chem. Int. Ed. 1978, 17, 522-524. [CrossRef]

42. Kotsantis, P.; Silva, L.M.; Irmscher, S.; Jones, R.M.; Folkes, L.; Gromak, N.; Petermann, E. Increased global transcription activity as a mechanism of replication stress in cancer. Nat. Commun. 2016, 7, 13087. [CrossRef] [PubMed]

43. Fantin, V.R.; St-Pierre, J.; Leder, P. Attenuation of LDH-A expression uncovers a link between glycolysis, mitochondrial physiology, and tumor maintenance. Cancer Cell 2006, 9, 425-434. [CrossRef] [PubMed] 
44. Zielonka, J.; Joseph, J.; Sikora, A.; Hardy, M.; Ouari, O.; Vasquez-Vivar, J.; Cheng, G.; Lopez, M.; Kalyanaraman, B. Mitochondriatargeted triphenylphosphonium-based compounds: Syntheses, mechanisms of action, and therapeutic and diagnostic applications. Chem. Rev. 2017, 117, 10043-10120. [CrossRef] [PubMed]

45. Evers, M.; Poujade, C.; Soler, F.; Ribeill, Y.; James, C.; Lelievre, Y.; Gueguen, J.C.; Reisdorf, D.; Morize, I.; Pauwels, R.; et al. Betulinic acid derivatives: A new class of human immunodeficiency virus type 1 specific inhibitors with a new mode of action. J. Med. Chem. 1996, 39, 1056-1068. [CrossRef]

46. Kashiwada, Y.; Hashimoto, F.; Cosentino, L.M.; Chen, C.H.; Garrett, P.E.; Lee, K.H. Betulinic acid and dihydrobetulinic acid derivatives as potent anti-HIV agents. J. Med. Chem. 1996, 39, 1016-1017. [CrossRef]

47. Soler, F.; Poujade, C.; Evers, M.; Carry, J.C.; Henin, Y.; Bousseau, A.; Huet, T.; Pauwels, R.; DeClercq, E.; Mayaux, J.F.; et al. Betulinic acid derivatives: A new class of specific inhibitors of human immunodeficiency virus type 1 entry. J. Med. Chem. 1996, 39, 1069-1083. [CrossRef]

48. Li, F.; Goila-Gaur, R.; Salzwedel, K.; Kilgore, N.R.; Reddick, M.; Matallana, C.; Castillo, A.; Zoumplis, D.; Martin, D.E.; Orenstein, J.M.; et al. PA-457: A potent HIV inhibitor that disrupts core condensation by targeting a late step in Gag processing. Proc. Natl. Acad. Sci. USA 2003, 100, 13555-13560. [CrossRef]

49. Schur, F.K.M.; Obr, M.; Hagen, W.J.H.; Wan, W.; Jakobi, A.J.; Kirkpatrick, J.M.; Sachse, C.; Krausslich, H.G.; Briggs, J.A.G. An atomic model of HIV-1 capsid-SP1 reveals structures regulating assembly and maturation. Science 2016, 353, 506-508. [CrossRef]

50. Adamson, C.S.; Sakalian, M.; Salzwedel, K.; Freed, E.O. Polymorphisms in Gag spacer peptide 1 confer varying levels of resistance to the HIV-1 maturation inhibitor bevirimat. Retrovirology 2010, 7, 1-8. [CrossRef]

51. Lu, W.X.; Salzwedel, K.; Wang, D.; Chakravarty, S.; Freed, E.O.; Wild, C.T.; Li, F. A single polymorphism in HIV-1 subtype C SP1 is sufficient to confer natural resistance to the maturation inhibitor bevirimat. Antimicrob. Agents Chemother. 2011, 55, 3324-3329. [CrossRef]

52. Van Baelen, K.; Salzwedel, K.; Rondelez, E.; Van Eygen, V.; De Vos, S.; Verheyen, A.; Steegen, K.; Verlinden, Y.; Allaway, G.P.; Stuyver, L.J. Susceptibility of human immunodeficiency virus type 1 to the maturation inhibitor bevirimat is modulated by baseline polymorphisms in Gag spacer peptide 1. Antimicrob. Agents Chemother. 2009, 53, 2185-2188. [CrossRef]

53. Coric, P.; Turcaud, S.; Souquet, F.; Briant, L.; Gay, B.; Royer, J.; Chazal, N.; Bouaziz, S. Synthesis and biological evaluation of a new derivative of bevirimat that targets the Gag CA-SP1 cleavage site. Eur. J. Med. Chem. 2013, 62, 453-465. [CrossRef]

54. Wang, D.; Lu, W.X.; Li, F. Pharmacological intervention of HIV-1 maturation. Acta Pharm. Sin. B 2015, 5, 493-499. [CrossRef]

55. Gu, M.; Zhao, P.; Zhang, S.Y.; Fan, S.J.; Yang, L.; Tong, Q.C.; Ji, G.; Huan, C. Betulinic acid alleviates endoplasmic reticulum stress-mediated nonalcoholic fatty liver disease through activation of farnesoid X receptors in mice. Brit. J. Pharmacol. 2019, 176, 847-863. [CrossRef]

56. Ye, Y.Q.; Zhang, T.; Yuan, H.Q.; Li, D.F.; Lou, H.X.; Fan, P.H. Mitochondria-targeted lupane triterpenoid derivatives and their selective apoptosis-inducing anticancer mechanisms. J. Med. Chem. 2017, 60, 6353-6363. [CrossRef] [PubMed]

57. Dubinin, M.V.; Semenova, A.A.; Ilzorkina, A.I.; Mikheeva, I.B.; Yashin, V.A.; Penkov, N.V.; Vydrina, V.A.; Ishmuratov, G.Y.; Sharapov, V.A.; Khoroshavina, E.I.; et al. Effect of betulin and betulonic acid on isolated rat liver mitochondria and liposomes. Biochim. Biophys. Acta-Biomembr. 2020, 1862. [CrossRef] [PubMed]

58. Dubinin, M.V.; Semenova, A.A.; Nedopekina, D.A.; Davletshin, E.V.; Spivak, A.Y.; Belosludtsev, K.N. Effect of F16-betulin conjugate on mitochondrial membranes and its role in cell death initiation. Membranes 2021, 11, 352. [CrossRef]

59. Dubinin, M.V.; Semenova, A.A.; Ilzorkina, A.I.; Penkov, N.V.; Nedopekina, D.A.; Sharapov, V.A.; Khoroshavina, E.I.; Davletshin, E.V.; Belosludtseva, N.V.; Spivak, A.Y.; et al. Mitochondria-targeted prooxidant effects of betulinic acid conjugated with delocalized lipophilic cation F16. Free Radic. Bio. Med. 2021, 168, 55-69. [CrossRef] [PubMed]

60. Wang, X.; Lu, X.C.; Zhu, R.L.; Zhang, K.X.; Li, S.; Chen, Z.J.; Li, L.X. Betulinic acid induces apoptosis in differentiated PC12 cells via ROS-mediated mitochondrial pathway. Neurochem. Res. 2017, 42, 1130-1140. [CrossRef] [PubMed] 